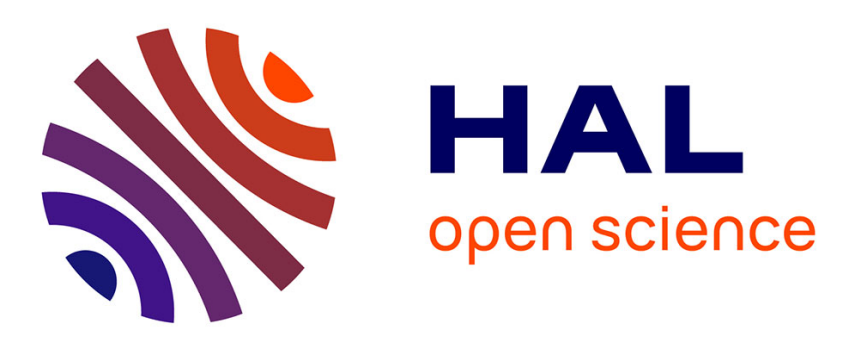

\title{
Targeted Tshz3 deletion in corticostriatal circuit components segregates core autistic behaviors
}

Xavier Caubit, Paolo Gubellini, Pierre L. Roubertoux, Michèle Carlier, Jordan Molitor, Dorian Chabbert, Mehdi Metwaly, Pascal Salin, Ahmed Fatmi, Yasmine Belaidouni, et al.

\section{To cite this version:}

Xavier Caubit, Paolo Gubellini, Pierre L. Roubertoux, Michèle Carlier, Jordan Molitor, et al.. Targeted Tshz3 deletion in corticostriatal circuit components segregates core autistic behaviors. 2021. hal-03388780

\author{
HAL Id: hal-03388780 \\ https://hal.science/hal-03388780
}

Preprint submitted on 20 Oct 2021

HAL is a multi-disciplinary open access archive for the deposit and dissemination of scientific research documents, whether they are published or not. The documents may come from teaching and research institutions in France or abroad, or from public or private research centers.
L'archive ouverte pluridisciplinaire HAL, est destinée au dépôt et à la diffusion de documents scientifiques de niveau recherche, publiés ou non, émanant des établissements d'enseignement et de recherche français ou étrangers, des laboratoires publics ou privés. 
1 Title

\section{Targeted Tshz3 deletion in corticostriatal circuit components segregates core autistic behaviors}

\section{Authors}

Xavier Caubit $^{1 \dagger}$, Paolo Gubellini ${ }^{1 \dagger}$, Pierre L. Roubertoux ${ }^{2 \dagger}$, Michèle Carlier ${ }^{3 \dagger}$, Jordan Molitor ${ }^{1}$, Dorian Chabbert $^{1}$, Mehdi Metwaly ${ }^{1}$, Pascal Salin ${ }^{1}$, Ahmed Fatmi ${ }^{1}$, Yasmine Belaidouni ${ }^{1}$, Lucie Brosse ${ }^{1}$, Lydia Kerkerian-Le Goff ${ }^{1 *}$, Laurent Fasano ${ }^{1 *}$

\section{Affiliation}

${ }^{1}$ Aix-Marseille Univ, CNRS, IBDM, UMR7288, Marseille, France.

${ }^{2}$ Aix-Marseille Univ, INSERM, MMG, UMR1251, Marseille, France.

${ }^{3}$ Aix-Marseille Univ, CNRS, LPC, UMR7290, Marseille, France.

†These authors contributed equally to this work.

\section{${ }^{*}$ Correspondence:}

laurent.fasano@univ-amu.fr ; lydia.kerkerian-le-goff@univ-amu.fr

\section{Abstract}

We previously linked TSHZ3 haploinsufficiency to autism spectrum disorder (ASD) and showed that embryonic or postnatal $T s h z 3$ deletion in mice results in behavioral traits relevant to the two core domains of ASD, namely social interaction deficits and repetitive behaviors. Here, we provide evidence that cortical projection neurons (CPNs) and striatal cholinergic interneurons (SCINs) are two main and complementary players in the TSHZ3-linked ASD syndrome. We show that in the cerebral cortex, TSHZ3 is expressed in CPNs and in a proportion of GABA interneurons, while not in cholinergic interneurons or glial cells. TSHZ3expressing cells, which are predominantly SCINs in the striatum, represent a low proportion of neurons in the ascending cholinergic projection system. We then characterized two new conditional knockout (cKO) models generated by crossing Tshz3 $3^{\text {floxflox }}$ with Emx1-Cre (Emx1-cKO) or Chat-Cre (Chat-cKO) mice to decipher the respective role of CPNs and SCINs. Emx1-cKO mice show altered excitatory synaptic transmission onto CPNs and plasticity at corticostriatal synapses, with neither cortical neuron loss nor impaired layer distribution. These animals present social interaction deficits but no repetitive patterns of behavior. Chat-cKO mice exhibit no loss of SCINs but changes in the electrophysiological properties of these interneurons, associated with repetitive patterns of behavior without social interaction deficits. Therefore, dysfunction in either CPNs or SCINs segregates with a distinct ASD behavioral trait. These findings provide novel insights onto the implication of the corticostriatal circuitry in ASD by revealing an 
unexpected neuronal dichotomy in the biological background of the two core behavioral domains of this disorder.

\section{KEYWORDS}

Autism spectrum disorder (ASD), cortical projection neurons, sociability, stereotyped behaviors, striatal cholinergic interneurons.

\section{INTRODUCTION}

Autism spectrum disorder (ASD) includes a heterogeneous group of neurodevelopmental pathologies the diagnosis of which is based exclusively on behavioral criteria. The two behavioral domains that are selected by the DSM-5 are: i) deficit in social communication and ii) restrictive, repetitive patterns of behavior, interests, or activities ${ }^{1}$. These domains also emerge from factor analyses of the 13 available diagnostic instruments in patients ${ }^{2}$ and in a model that aligns mouse and patient features ${ }^{3}$. More than 900 genes have been liked to $\mathrm{ASD}^{4}$, among which >100 impact synaptic functions or interact with genes involved in neuronal development ${ }^{5}$. As a possible neurobiological substrate, clinical and animal studies point to molecular, neurodevelopmental and functional changes of deep-layer cortical projection neurons (CPNs), in particular those of layer 5 (L5) forming the corticostriatal pathway ${ }^{6-9}$. In this context, we have linked heterozygous TSHZ3 gene deletion to a syndrome characterized by neurodevelopmental disorders including autistic behavior, cognitive disabilities and language disturbance, with some patients also showing renal tract abnormalities ${ }^{10}$. TSHZ3 encodes the highly conserved, zinc-finger homeodomain transcription factor TSHZ3, and has been identified in networks of human neocortical genes highly expressed during late fetal development, which are involved in neurodevelopmental and neuropsychiatric disorders ${ }^{9,}{ }^{10}$. It is now ranked as a high-confidence risk gene for ASD (https://gene.sfari.org/database/humangene/TSHZ3\#reports-tab). In human and mouse, high TSHZ3 gene or protein expression is detectable in the cortex during pre- and postnatal development ${ }^{11}$. We showed that heterozygous deletion of Tshz3 $\left(\right.$ Tshz3 $^{+/ l a c z}$ ) and conditional early postnatal knockout $(\mathrm{KO})$ using the Camk2a-Cre promoter (Camk2a-cKO mice) lead to ASD-relevant behavioral deficits paralleled by changes in cortical gene expression and corticostriatal synaptic abnormalities ${ }^{10,12}$. These data suggest that $T s h z 3$ plays a crucial role in both preand postnatal brain development and functioning, and point to CPNs, and in particular to the corticostriatal pathway, as a main player in the Tshz3-linked ASD syndrome. In the mouse striatum, TSHZ3 is not expressed in striatal spiny projection neurons (SSPNs), which represent $>90 \%$ of striatal neurons, but in a small population of cells that are likely interneurons ${ }^{10}$. We ${ }^{13}$ and others ${ }^{14,15}$ identified these cells as being mainly striatal cholinergic interneurons (SCINs), whose implication in ASD has been suggested by some studies ${ }^{16,17}$. We also showed that the Camk2a-Cre transgene is unexpectedly expressed in the SCIN lineage, where it efficiently elicits the deletion of Tshz3 in Camk2a-Cre mice ${ }^{13}$. Together, these data 
$T s h z 3^{+/ l a c z}$ heterozygous ${ }^{10}$, but also in Camk2a-cKO mice ${ }^{12}$, which both show the full repertoire of ASDlike behavioral defects. We thus here aimed at investigating the respective contribution of CPNs and SCINs to the pathophysiology of Tshz3-linked ASD using targeted conditional deletion of this gene, and provide evidence for the complementary implication of these two neuronal populations in the ASD-related core features.

\section{RESULTS}

\section{Conditional deletion of Tshz3 in CPNs}

High levels of Tshz3 gene or TSHZ3 protein expression are detectable in the mouse cortex during pre- and postnatal development ${ }^{10,11}$. In the adult cerebral cortex, TSHZ3 is detected in the great majority of CPNs (Caubit et al., 2016). Here, performing immunostaining for beta-galactosidase ( $ß-G a l)$ to report the expression of $T s h z 3$, we show that $T s h z 3$ is also expressed in part of cortical GABAergic interneurons, as evidenced using Tshz3+/lacz;GAD67-GFP mice (Fig. S1a). Quantitative analysis indicates that $29.6 \pm 1.4 \%$ of cortical GAD67-expressing neurons co-express $B-G a l$ and that these dually stained neurons are rather uniformly distributed among superficial $(43.2 \pm 2.0 \%)$ and deep $(56.8 \pm 2.0 \%)$ cortical layers $(n=12$ sections from 2 mice). In contrast, $ß-G a l$ is not detectable in cortical choline acetyltransferase (CHAT) positive neurons (Fig. S1b), Olig2-positive oligodendrocytes (Fig. S1c) and GFAP-positive astrocytes (Fig. S1d, e). To address the role of Tshz3 in CPNs, Tshz3 floxflox mice were crossed with Emx1-Cre (empty spiracle homeobox 1) mice (Emx1-cKO). The Emx1-Cre mouse expresses the Cre-recombinase in the progenitors of cortical glutamatergic projection neurons (i.e., CPNs) and glial cells from embryonic day 9 (E9), but neither in those of cortical GABAergic neurons, nor of striatal interneurons, including cholinergic ones ${ }^{18}$. Therefore, in the corticostriatal circuitry of Emx1-cKO mice, Tshz3 function should be specifically lost in CPNs. Compared to control, Emx1-cKO mice show a drastic reduction of Tshz3 mRNA levels and of the density of TSHZ3-positive cells in the cerebral cortex, showing the efficacy of the deletion, while the density of striatal cells expressing TSHZ3 is unchanged (Fig. 1a-c). Despite the loss of Tshz3 expression in most CPNs, the density of NeuN-positive cells is unchanged (Fig. S2a, b), showing no neuronal loss; in addition, neither the pattern of expression of layer-specific CPN markers, namely CUX1 for L2-4 and BCL11B for L5-6, nor the density of cells expressing these markers is affected (Fig. S2c, d), indicating no major alteration in cortical layering. However, spine density of L5 CPNs from Thy1-GFP-M;Emx1-CKO mice is significantly reduced compared to Thy1-GFP-M control mice (Fig. 1d, e). By crossing Emx1-cKO with GAD67-GFP mice, we show that cortical GABAergic neurons still express TSHZ3 (Fig. 1f), confirming the specificity of Tshz3 deletion in CPNs. To study whether Tshz3 loss in CPNs could indirectly affect cortical GABAergic interneurons, we compared GAD67-GFP control mice (Control-GAD67-GFP) to Emx1-cKO-GAD67-GFP mutant mice. No significant changes in the number of GABAergic interneurons (Control-GAD67-GFP: 140.7 
$110 \pm 4.9, \mathrm{n}=37$ sections from 5 mice; Emx1-cKO-GAD67-GFP: $144.6 \pm 6.1, \mathrm{n}=41$ sections from 7 mice; $P=$ 1110.624 , Student's $t$-test) and in their distribution are found (Fig. S3a, b). CHAT immunostaining on striatal 112 slices in Emx1-cKO mice also shows no significant modification of the density of SCINs (Fig. S3c, d).

\section{Cortical excitatory synaptic transmission and corticostriatal synaptic plasticity in Emx1-cKO mice} L5 CPNs recorded in slices from Emx1-cKO mice show no significant changes in their membrane properties and excitability compared to control (Fig. S4a-e). Action potential (AP)-dependent glutamate release onto L5 CPNs, evaluated by measuring paired-pulse ratio, is also unaffected (Fig. S4f), while both NMDA/AMPA ratio (Fig. S4g) and NMDA-induced currents (Fig. S4h) are significantly reduced, suggesting decreased NMDA receptor-mediated signaling in Emx1-cKO mice. The amplitude of AMPA receptor-mediated miniature excitatory postsynaptic currents (mEPSCs) is similar in control and Emx1-cKO mice (Fig. S4i), further arguing for the implication of NMDA but not AMPA receptors. Conversely, mEPSC frequency is reduced (Fig. S4i), suggesting decreased AP-independent glutamate release onto L5 CPNs and/or reduced number of active excitatory synapses in Emx1-cKO mice, consistent with the decreased spine density on L5 CPNs (Fig. 1d, e).

SSPNs recorded in slices from Emx1-cKO mice show electrophysiological properties (Fig. S4A-D) and basal corticostriatal synaptic transmission (Fig. S5e-g) similar to control. However, both long-term potentiation (LTP) and long-term depression (LTD) at corticostriatal synapses are abolished in Emx1-cKO mice (Fig. 2), confirming a critical role of $T s h z 3$ in the functioning of the corticostriatal circuit.

\section{Conditional deletion of $T s h z 3$ in cholinergic neurons}

Dual immunodetection of CHAT and $B-G a l$ in $T s h z 3^{+/ l a c z}$ mice was performed to analyze the expression of Tshz3 in brain cholinergic neuron populations. This was preferred to dual immunodetection of CHAT and TSHZ3 since the tissue fixation conditions for obtaining optimal detection of each protein are different, and since TSHZ3 immunodetection provides weaker labeling and higher background than ß-Gal immunodetection. As reported previously ${ }^{13}$, virtually all SCINs express Tshz3 (Fig. S6a, h). In contrast, there are no or a little proportion (<30\%) of B-Gal-positive cells within CHAT-positive neurons in the components of the basal forebrain cholinergic system (medial septal nucleus, diagonal band nuclei, nucleus basalis of Meynert and substantia innominata) (Fig. S6a-d, h). SCINs thus represent the major population of Tshz3-expressing cells among the forebrain cholinergic neurons. In addition, there is almost no coexpression of $\mathrm{B}-\mathrm{Gal}$ and CHAT in the pedunculopontine (Fig. S6e, f, h) and laterodorsal tegmental nuclei (Fig. S6g, h), which are known to provide cholinergic afferents to several brain areas including the striatum 19. Among the other brainstem nuclei, co-expression ranges from poor to extensive, as illustrated in the parabigeminal nucleus and the oculomotor nucleus, respectively (Fig. S6e, f, h). mice (Chat-cKO model). CHAT is expressed in the brain from early embryonic development and as soon 
146 as E18.5 in the striatum ${ }^{20}$. TSHZ3 immunostaining in Chat-cKO mice confirms a significant loss of TSHZ3 147 in SCINs (Fig. 3a, b), which does not affect the number of striatal CHAT-positive cells (Fig. 3c, d). This result 148 was confirmed using Chat-Cre;Ai14Flox/+ mice (Chat-Cre;Rosa26-STOP-Tomato) to visualize SCINs in the 149 presence or absence of Tshz3 (Fig. 3e, f).

\section{Tshz3 loss and SCIN electrophysiological properties}

152 In acute brain slices, SCINs are easily recognizable among the other striatal neurons due to their larger soma ${ }^{21}$. Moreover, they are the only autonomously active cells, firing action APs with either a regular, irregular or bursting pattern ${ }^{22,23}$. SCINs also show a characteristic depolarizing voltage sag in response to the injection of negative current pulses due to the activation of the nonspecific $/ \mathrm{h}$ cation current mediated by $\mathrm{HCN}$ channels, which largely contributes to the spontaneous AP discharge characterizing these neurons ${ }^{23-}$ spontaneous AP discharge, its regularity [expressed as the coefficient of variation (CV) of the inter-AP intervals], and the amplitude of the sag [expressed as voltage sag ratio (VSR)] in SCINs from Chat-cKO mice and control littermates (Fig. 4a-C). We found that SCINs recorded from Chat-cKO mice show a significant reduction of both VSR (Fig. 4d) and spontaneous firing frequency (Fig. 4e), as well as an increased CV of inter-AP intervals that suggests a less regular discharge activity (Fig. 4f). The resting membrane potential at steady state is similar between control vs. Chat-cKO SCINs (46.64 \pm 0.68 vs. 45.65 $\pm 0.64 \mathrm{mV}, 56 \mathrm{vs}$. $86 \mathrm{SCINs}$, respectively; $\mathrm{P}=0.305$, Student's $t$-test), while the current-voltage relationship reveals a slight but significant increase of input resistance in Chat-cKO SCINs vs. control, calculated as the slope of the linear best fit (Fig. 4 g; $125.7 \pm 4.5$ vs. $107.5 \pm 4.0 \mathrm{M} \Omega$, respectively; $F(1,911)=8.816, P=$ $0.0031)$.

\section{Conditional deletion of Tshz3 in CPNs or in cholinergic neurons segregates the two core behavioral domains of ASD}

171 For behavioral experiments, only male $E m \times 1-c K O, C h a t-c K O$ and control littermate mice were used. Neither

$172 E m \times 1-c K O$ nor Chat-cKO mice present visual, auditory and olfactory impairment $v s$. their respective control

173 (Fig. S7). They were then tested for deficits in social behavior, the first core feature of ASD, as well for

174 stereotyped/repetitive patterns of behavior and for restricted field of interests, which are subcategories of

175 the second ASD core feature.

176 During the habituation phase in the two-chamber test, both Emx1-cKO and Chat-cKO mice show no 177 significant differences in their exploration of the lured boxes as compared to their respective controls $(P=$ $1780.14, \eta^{2}=0.12, P=0.84, \eta^{2}=0.002$, respectively Fig. 5a). However, Emx1-cKO but not Chat-cKO mice 179 show impaired social relationships (Fig. 5). Emx1-cKO mice have less preference than their controls for a 180 conspecific (sociability, Fig. 5b) and for an unfamiliar male (social novelty, Fig. 5c), the interaction between 
genotype and box content being large in each case, as shown by the effect size that exceeds the typical range of variation (Fig. $5 \mathrm{~d}$ ).

Conversely, Chat-cKO but not Emx1-cKO mice present more stereotyped or repetitive patterns of behavior than their controls, as shown by the marble burying score, time burrowing in a new cage, stereotyped dips on a hole board, and number of leanings in an open field (Fig. 6a-d), with a large effect size (Fig. 6e). Restricted field of interest is impacted neither in Emx1-cKO nor in Chat-cKO mice (Fig. S8ac). Finally, hind paw coordination is impaired in Chat-cKO but not in Emx1-cKO mice (Fig. S8d, e), while spatial learning ability is unaffected in both models (Fig. S8f-i).

\section{DISCUSSION}

Previous studies showed that haploinsufficiency or postnatal deletion of Tshz3 results in ASD-relevant behavioral deficits and suggested altered function of the corticostriatal circuitry as a possible substrate ${ }^{10}$, 12. The present findings point to SCINs as an additional player in the Tshz3-linked ASD syndrome. They also provide evidence that targeted conditional deletion of Tshz3 in either CPNs (Emx1-cKO) or cholinergic neurons (Chat-cKO) segregates the two core behavioral traits used to diagnose ASD, respectively social behavior deficits and repetitive behavioral patterns, suggesting that alterations in CPNs and in SCINs contribute in a complementary manner to the repertoire of behavioral deficits linked to Tshz3 deficiency. Restricted field of interest, which defines a sub-category of the second ASD domain, was observed neither in Emx1-cKO nor in Chat-cKO mice, suggesting that the expression of this deficit in the previously characterized models of $T s h z 3$ deletion may involve additional players, and/or result from the combined dysfunction of CPNs and SCINs due to the loss of Tshz3 in both these neuronal types. Learning ability was impacted neither by Tshz3 postnatal deletion ${ }^{12}$, nor in Emx1-cKO and Chat-cKO models. the cortex ${ }^{26,27}$. In particular, corticostriatal and striatal circuit dysfunctions are associated to ASD features, both in patients and in mouse models, with CPNs and SSPNs being highly impacted by mutations of ASDlinked genes $7,8,10,12,28,29$. There is however increasing evidence incriminating interneuron populations of the cortex and the striatum in ASD ${ }^{30}$. Here, we show that, in the cortex, the ASD-related Tshz3 gene is expressed not only in CPNs but also in a third of GABA interneurons, while not in cholinergic interneurons. In contrast, in the striatum, the vast majority of Tshz3-expressing cells are cholinergic interneurons ${ }^{13}$. To disentangle the role of CPNs from that of interneurons in the ASD symptoms linked toTshz3 deficiency, we generated and characterized Emx1-cKO mice. We confirmed the specificity of Tshz3 deletion in CPNs within the corticostriatal circuit in this model, Tshz3 expression in cortical and striatal interneurons being maintained. In addition, no change in the numbers and positioning of these interneurons were detected. Interestingly, we found that Emx1-cKO mice specifically exhibit impaired social behavior, and that this deficit co-segregates with altered NMDA receptor-mediated transmission in the cortex and disrupted plasticity at corticostriatal synapses. Corticostriatal synaptic plasticity has been deeply characterized, but discrepancies 
217 concerning its induction protocols and the underlying molecular and cellular mechanisms ${ }^{31}$ make it difficult 218 to univocally interpret our results. However, since LTD expression mainly involves presynaptic changes ${ }^{32}$, 219 its disruption in Emx1-cKO mice could be attributable to cortical circuitry defects, such as the observed 220 decrease of NMDA receptor activity in L5 CPNs that could impair corticostriatal output. LTP expression 221 mostly depends upon postsynaptic mechanisms ${ }^{32}$, but presynaptic NMDA receptors also play a role ${ }^{33,}{ }^{34}$. 222 The lack of changes in SSPNs electrophysiological properties or basal corticostriatal transmission rather 223 favors a presynaptic hypothesis to explain this loss of LTP. Moreover, our findings are in line with studies 224 substantiating the involvement of NMDA receptor dysfunction in social deficits associated with ASD in rodent 225 models as well as in patients ${ }^{35}$, 36 . Finally, consistent with the literature linking ASD with changes of dendritic 226 spine density ${ }^{37}$, we evidence decreased spine density in L5 CPNs of Emx1-cKO mice, as in our previous 227 model ${ }^{12}$. Overall, these data indicate that the loss of Tshz3 in CPNs induces morphofunctional changes in 228 these neurons and deeply affects corticostriatal plasticity, which might result in altered processing of cortical information and account for the observed social behavior deficits.

We also investigated the contribution of cholinergic neurons in the pathophysiology of Tshz3-linked ASD. We show that TSHZ3 is expressed in almost $100 \%$ of SCINs, while its expression is absent or partial 232 in the other main brain cholinergic systems. Despite their low number, SCINs have morphofunctional 233 features that place them as key modulators of striatal microcircuits. They play a crucial role in movement 234 control, attentional set-shifting, habit-mediated and goal-directed behavior, and selection of appropriate 235 behavioral responses to changes in environmental contingencies, conferring behavioral flexibility ${ }^{38-42}$. 236 These interneurons are also involved in basal ganglia-related pathologies such as dystonia, Parkinson's 237 and Huntington's disease, Tourette's syndrome, obsessive compulsive disorder and drug addiction ${ }^{43-45}$. In 238 contrast, despite the array of data pointing to basal ganglia and cholinergic transmission abnormalities in 239 ASD and in ASD models ${ }^{16,46-50}$, to date there is little evidence showing the specific involvement of SCINs: 240 the partial depletion of both SCINs and fast-spiking GABAergic interneurons produces stereotypy and 241 impaired social behavior in male mice ${ }^{17}$, while total elimination of SCINs results in perseverative behavior 242 that extends to social behavior, rather reminiscent of neuropsychiatric conditions as Tourette's syndrome or 243 obsessive compulsive disorder ${ }^{51}$. The present work reveals that targeted Tshz3 deletion in CHAT244 expressing neurons leads to robust stereotyped and repetitive patterns of behavior without impacting social 245 behavior. Given the literature associating drug-induced stereotypies with abnormalities in striatal cholinergic 246 signaling ${ }^{52-54}$, and the co-expression of CHAT and TSHZ3 in SCINs but not in brainstem cholinergic neurons 247 that are known to project to the striatum ${ }^{19}$, this behavioral deficit is likely attributable to SCINs. Whereas 248 the number of SCIN in Chat-cKO mice is unchanged, suggesting that their generation and viability is not 249 affected, we evidenced modifications in their firing activity and electrophysiological membrane properties. 250 This finding is an addition to the increasing amount of data stressing the complex implication of SCINs in 251 health and diseases ${ }^{55}$. How the selective loss of Tshz3 in SCINs leads to these electrophysiological 252 changes, what are their molecular bases and what are the consequences on striatal cholinergic signaling 
253 still need to be determined. However, SCINs are important modulators of the two populations of SSPNs 254 forming the "direct" and "indirect" pathways by which the striatum regulates basal ganglia outflow, whose 255 balanced activity is determinant for appropriate action selection ${ }^{40,56}$. Thus, the changes in SCIN properties 256 observed here could alter the way they normally respond to salient stimuli and/or reward-associated cues, 257 thereby the way they modulate the transfer of cortical information through the striatum ${ }^{38,39,57}$, as observed 258 after targeted deletion of the transcription factor Er81 in SCINs ${ }^{42}$. This could underlie the increased 259 stereotyped behaviors observed in Chat-cKO mice and, possibly, also in $T s h z 3^{+/ l a c z}{ }^{10}$, as well as in postnatal $260 T s h z 3 \mathrm{cKO}^{12}$ in which we recently showed that Tshz3 is lost also in SCINs ${ }^{13}$. Finally, Chat-cKO mice do not 261 show basal exploration deficit, similarly to Emx1-cKO mice, but present impaired hind paw coordination, 262 which is in line with motor deficiencies frequently associated with ASD ${ }^{58}$ and with a study linking partial 263 SCIN ablation with motor incoordination ${ }^{59}$. Although TSHZ3 is expressed in about $25 \%$ of cholinergic 264 neurons of the nucleus basalis of Meynert and the substantia innominata, the similarity of spatial learning 265 curves of control and Chat-cKO mice suggests minor impact of Tshz3 deletion on the function of the basal 266 forebrain cholinergic system, which is deeply involved in learning and memory processes ${ }^{60}=$

In conclusion, this study shows that the conditional loss of the ASD-related gene Tshz3 in CPNs 268 and SCINs does not affect the numbers of these neurons but induces profound changes in their 269 electrophysiological and synaptic properties, associated with specific ASD-like behavioral defects. To our 270 knowledge, it represents the first demonstration in mice models that the two behavioral domains used to 271 diagnose ASD are independent domains that can be underpinned by dysfunction in distinct neuronal 272 subtypes, in this case two components of the corticostriatal circuitry. These findings may open the road to 273 domain-specific pharmacological and behavioral therapies. 


\section{MATERIALS and METHODS}

\section{DATA AVAILABILITY}

The data that support the findings of this study are available from the corresponding author upon reasonable request. Raw data (FastQ files) from the sequencing experiment (triplicates from wild-type and Tshz3mutant striatum) and raw abundance measurements for genes (read counts) for each sample are available from Gene Expression Omnibus (GEO) under accession GSE157658, which should be quoted in any manuscript discussing the data.

The Tshz3 $3^{l a c z}$, Tshz3 $3^{\text {floxflox }}$, Emx1-Cre, Chat-Cre, Rosa26-STOP-lacZ and Ai14 (Rosa26-STOP-Tomato), GAD67-GFP and Thy1-GFP mouse lines have been described previously 10, 12, 18, 61-66. Male heterozygous Cre mice were crossed with female $T s h z 3^{\text {flox } f \text { flox }}$ to generate the two $T s h z 3$ conditional knockout (cKO) mice models: Emx1-cKO and Chat-cKO ${ }^{18,64}$. Littermate Emx1-Cre- ${ }^{-/}$and Chat-Cre-- mice were used as respective controls. Animals carrying the $T s h z 3^{\text {flox }}$ allele and $T s h z 3^{\Delta}$ allele were genotyped as described previously ${ }^{12}$. Experimental procedures were in agreement with the recommendations of the European Communities Council Directive (2010/63/EU). They have been approved by the "Comité National de Réflexion Ethique sur l'Expérimentation Animale n'14" and the project authorization delivered by the French Ministry of Higher Education, Research and Innovation. (ID numbers 57-07112012, 2019020811238253-V2 \#19022 and 2020031615241974-V5 \#25232).

\section{IMMUNOHISTOCHEMISTRY AND HISTOLOGY}

All stains were processed on coronal brain sections of postnatal day $(P)$ 28-34 mice. Immunostaining for TSHZ3 alone was performed on cryostat sections of brains immediately removed after anesthesia (ketamine + xylazine, $100+10 \mathrm{mg} / \mathrm{kg}$, respectively, i.p.) and frozen in dry ice until use. Before incubation with the antibodies, sections were fixed with $4 \%$ paraformaldehyde for $15 \mathrm{~min}$, then washed twice for $5 \mathrm{~min}$ in PBS. For TSHZ3 immunostaining and GFP detection, GAD67-GFP mice were anesthetized (see above) and transcardially perfused with PBS. Brains were immediately dissected out, post-fixed by immersion 2 hours in $4 \%$ paraformaldehyde in PBS, placed in 30\% sucrose in PBS overnight and frozen in dry ice until sectioning. For the other stains, mice were anesthetized (see above) and transcardially perfused with $4 \%$ paraformaldehyde (PFA) in $0.1 \mathrm{M}$ phosphate buffer. Brains were removed and post-fixed in $4 \%$ PFA for at least $2 \mathrm{~h}$ before cryostat sectioning (40 $\mu \mathrm{m}$-thick). Brain sections were washed with PBS and blocked in 
311 in primary antibody diluted in blocking solution (PBST, 1\% BSA) overnight at $4^{\circ} \mathrm{C}$ with the following primary antibodies: mouse anti-NeuN (1:500, Millipore, Mab377), rat anti-BCL11B (1:1,000, Abcam, ab18465), goat anti-CHAT (1:100, Millipore, AB144P), rabbit anti-ß-Galactosidase (1:1,000, Cappel, 599762), goat antiCDP/CUX1 (1:200, Santa Cruz Biotechnology, C20, SC6327) and guinea-pig anti-TSHZ3 (1:2,000; ref. $\left.{ }^{61}\right)$. Sections were then washed with PBS three times and incubated overnight at $4^{\circ} \mathrm{C}$ in secondary antibodies diluted 1:1,000 in blocking solution: donkey anti-rabbit Cy3, donkey anti-guinea pig Cy3 and donkey antigoat Cy3 (Jackson ImmunoResearch Laboratories) and goat anti-mouse Alexa Fluor 488, goat anti-rat Alexa Fluor 555 and donkey anti-goat Alexa Fluor 488 (Life Technologies). Sections were counterstained by 5 min incubation in $300 \mu \mathrm{M}$ DAPI intermediate solution (1:1,000, Molecular Probes, Cat\# B34650). Section were then washed with PBS three times, mounted on Superfrost Plus slides (Fischer Scientific) and coverslipped for imaging on a laser scanning confocal microscope (Zeiss LSM780 with Quasar detection module). Spectral detection bandwidths ( $\mathrm{nm}$ ) were set at 411-473 for DAPI, 498-568 for GFP and 568-638 for Cy3; pinhole was set to 1 Airy unit. Unbiased stereological counting of NeuN, TSHZ3, CUX1, BCL11B, CHAT and $B-G a l$ positive neurons as well as of GAD-GFP neurons were done from confocal images using ImageJ software (see Figure legends for frame details). Images were assembled using Photoshop 21.2.3.

Cell counts were performed in the dorsal striatum (excluding the nucleus accumbens) and in the surrounding motor and sensorimotor cortex on sections spanning from bregma 0 to $+1.18 \mathrm{~mm}$, AP. The whole surface was analyzed for the striatum. For the cortex, counts were performed in frames of $400-\mu m$ width either spanning the total thickness of the cortex (NeuN), the thickness of specific layers or divided into 10 bins of equal size for the analysis of the distribution of Gad67GFP-positive cells. For the different cholinergic nuclei, the analyses were performed on sections spanning from bregma +0.62 to $+0.38 \mathrm{~mm}$ for $\mathrm{ms}$ and $\mathrm{hdb},-0.34$ to -0.8 for si and $\mathrm{nbm},+3.8$ to -4.16 for $3 \mathrm{~N},-4.16$ to -4.6 for pbg and pptg and -4.72 to -

\section{MORPHOMETRIC AND DENDRITIC SPINE ANALYSIS OF L5 CPNS}

We used transgenic mouse lines (P28) expressing Thy1-GFP (green fluorescent protein) in L5 CPNs ${ }^{66}$.

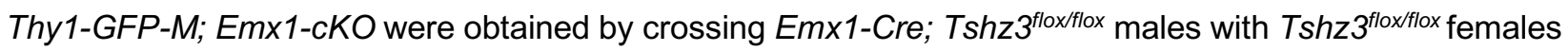
heterozygous for Thy1-GFP. Analysis of spine density and morphology was performed on stacks from 100 $\mu \mathrm{m}$-thick vibratome sections (1 $\mu \mathrm{m}$ z-step) on 4 littermate pairs using a Zeiss LSM780 (Oberkochen, 341 Germany) laser scanning confocal microscope (63X objective NA 1.4, $0.03 \mu \mathrm{m} / \mathrm{pixel}$, voxel size $0.033 \mu \mathrm{m}^{2}$ $342 \times 0.37 \mu \mathrm{m})$. Spine counts were obtained from second or third order basal dendritic branches of randomly 343 selected L5 CPNs. Dendrites from 5 to 7 cells were analyzed per animal, providing a cumulated dendrite 344 length $>750 \mu \mathrm{m}$ for each genotype. Spine identification and density measures were done using 345 NeuronStudio ${ }^{67}$. 


\section{RT-qPCR}

Total RNA from control and Tshz3 mutant (P28) cerebral cortex was prepared using RNeasy Plus Universal Mini Kit gDNA eliminator (Qiagen ${ }^{\mathrm{TM}}$ ) and first strand CDNA was synthesized using iScript Reverse Transcription Supermix kit (Bio-RAD ${ }^{\mathrm{TM}}$ ). Real-time quantitative PCR (RT-qPCR) was performed on a CFX96 qPCR detection system (Bio-RAD ${ }^{\mathrm{TM}}$ ) using SYBR® GreenER ${ }^{\mathrm{TM}}$ qPCR SuperMixes (Life Technologies ${ }^{\mathrm{TM}}$ ). RT-qPCR conditions: 40 cycles of $95^{\circ} \mathrm{C}$ for $15 \mathrm{~s}$ and $60{ }^{\circ} \mathrm{C}$ for $60 \mathrm{~s}$. Analyses were performed in triplicate. Transcript levels were first normalized to the housekeeping gene Gapdh. Primer sequences used for RTqPCR: Gapdh Forward: 5' GTCTCCTGCGACTTCAACAGCA 3'; Gapdh Reverse: 5' ACCACCCTGTTGCTGTAGCCGT 3'. Tshz3 Forward: 5' CACTCCTTCCAGCATCTCTGAG 3'; Tshz3 Reverse: 5' TAGCAGGTGCTGAGGATTCCAG 3'.

\section{ELECTROPHYSIOLOGY}

Electrophysiological data were obtained from $57 \mathrm{Em} \times 1-\mathrm{cKO}$ and $44 \mathrm{Em} \times 1-\mathrm{Cre}^{-/-}$control littermates, and from 16 Chat-cKO and 16 Chat-Cre $^{-/}$control littermates, aged P21-28. Procedures were similar to those cut using a $\mathrm{S} 1000$ Vibratome (Leica) in ice-cold solution containing (in $\mathrm{mM}$ ): 110 choline, $2.5 \mathrm{KCl}, 1.25$ $\mathrm{NaH}_{2} \mathrm{PO}_{4}, 7 \mathrm{MgCl}_{2}, 0.5 \mathrm{CaCl}_{2}, 25 \mathrm{NaHCO}_{3}, 7$ glucose, $\mathrm{pH}$ 7.4. Slices were kept at room temperature in oxygenated artificial cerebrospinal fluid (ACSF), whose composition was (in $\mathrm{mM}$ ): $126 \mathrm{NaCl}, 2.5 \mathrm{KCl}, 1.2$ $\mathrm{MgCl}_{2}, 1.2 \mathrm{NaH}_{2} \mathrm{PO}_{4}, 2.4 \mathrm{CaCl}_{2}, 11$ glucose and $25 \mathrm{NaHCO}_{3}, \mathrm{pH}$ 7.4. Electrophysiological recordings were performed in oxygenated artificial cerebrospinal fluid (ACSF) at $34-35{ }^{\circ} \mathrm{C}$, flowing at $\sim 2 \mathrm{ml} / \mathrm{min}$. L5 CPNs of the primary motor and somatosensory cortex, and SSPNs and SCINs of the dorsolateral striatum were identified by infrared video microscopy and by their electrophysiological properties ${ }^{69,70}$. They were recorded (in mM): $125 \mathrm{~K}$-gluconate, $10 \mathrm{NaCl}, 1 \mathrm{CaCl}_{2}, 2 \mathrm{MgCl}_{2}$, 0.5 BAPTA, 19 HEPES, $0.3 \mathrm{Na}$-GTP, and $1 \mathrm{Mg}-\mathrm{ATP}$, pH 7.3 (except for NMDA/AMPA ratio experiments, see below). Electrophysiological data were acquired by an AxoPatch 200B amplifier and pClamp 10.7 software (Molecular Devices, Wokingham, UK). Series and input resistance were continuously monitored by sending $5 \mathrm{mV}$ pulses, and neurons showing $\geq 20 \%$ change in these parameters were discarded from the analysis.

\section{Characterization of CPNs, SSPNs and synaptic transmission}

A stimulating bipolar electrode was placed either in the cortex at the level of $L 4$ to activate local fibers and evoke excitatory postsynaptic currents (EPSCs) in L5 CPNs, or in the corpus callosum to activate corticostriatal fibers and evoke EPSCs in SSPNs ${ }^{12}$. Glutamatergic EPSCs were recorded in the presence of $50 \mu \mathrm{M}$ picrotoxin at a holding potential of $-60 \mathrm{mV}$ (CPNs) or $-80 \mathrm{mV}$ (SSPNs). Spontaneous miniature 
EPSCs (mEPSCs) were recorded in the presence of $50 \mu \mathrm{M}$ picrotoxin and $1 \mu \mathrm{M}$ tetrodotoxin. Currentvoltage (I-V) relationship was obtained in current-clamp mode by injecting hyperpolarizing and depolarizing current steps $(\Delta \mathrm{I}= \pm 50 \mathrm{pA}, 800 \mathrm{~ms})$, and input resistance was calculated by linear regression analysis, i.e. as the slope of the linear best fit of the I-V relationship of each recorded neuron. Rheobase was measured as the minimal injected current ( $+5 \mathrm{pA}$ increments) capable of eliciting an action potential (AP). For pairedpulse ratio (PPR), EPSC amplitude was measured on 6 averaged traces at each inter-pulse interval. For analyzing mEPSCs, the detection threshold (around 3-4 pA) was set to twice the noise after trace filtering (Boxcar low-pass), and only cells exhibiting stable activity and baseline were considered. For NMDA/AMPA ratio experiments, the internal solution contained (in $\mathrm{mM}$ ): $140 \mathrm{CsCl}, 10 \mathrm{NaCl}, 0.1 \mathrm{CaCl}_{2}, 10 \mathrm{HEPES}, 1$ EGTA, $2 \mathrm{Mg}$-ATP and 0.5 Na-GTP, pH 7.3. The AMPA component of the EPSC was measured at the peak at a holding potential of $-60 \mathrm{mV}$, while the NMDA component was measured at $+40 \mathrm{mV}$ and $40 \mathrm{~ms}$ after the stimulation artifact, when the AMPA component is negligible, as previously described ${ }^{12}$. Tonic NMDA currents were elicited by bath application of $50 \mu \mathrm{M}$ NMDA for $60 \mathrm{~s}$, after a stable baseline of at least $120 \mathrm{~s}$; their amplitude was measured by averaging the current values of a $5 \mathrm{~s}$ window around the negative peak, compared to baseline; only neurons that were capable of returning to their baseline after washout were considered. EPSC amplitude for monitoring corticostriatal long-term depression and potentiation (LTD and LTP, respectively) was measured on averaged traces (6 per minute) to obtain time-course plots and to compare this parameter before (baseline) and after induction protocols. The induction protocol for corticostriatal LTD consisted of 3 trains at $100 \mathrm{~Hz}, 3 \mathrm{~s}$ duration, $20 \mathrm{~s}$ interval, at half intensity compared to baseline ${ }^{71}$. LTP induction protocol was identical but, during each train, neurons were depolarized to $-10 \mathrm{mV}$ to allow strong activation of NMDA receptors ${ }^{10,12,72}$. For a review about corticostriatal LTD and LTP see ${ }^{32}$.

\section{Characterization of SCINs}

The resting membrane potential (RMP) was measured at the steady state between two consecutive APs. The current-voltage relationship was calculated from the membrane response at the end of current steps from -200 to $-20 \mathrm{pA}$ (20 pA steps lasting $800 \mathrm{~ms}$ ). The voltage sag ratio (VSR) was calculated from the response to a $-120 \mathrm{pA}$ current step as the peak voltage drop (sag) against the voltage at the end of the current pulse ${ }^{73,74}$. Such relatively small current step was chosen because, with larger steps, the sag amplitude was extremely variable between different SCINs. Spontaneous AP firing was analyzed in terms of discharge frequency (expressed in $\mathrm{Hz}$ ) and regularity; to quantify this latter parameter, we calculated the coefficient of variation (CV) of the inter-AP intervals. Note that spontaneous AP firing was analyzed only from cell-attached recordings, which were done before switching to whole-cell; in some cases, spontaneous firing was not detectable in cell-attached configuration, thus the number of samples for AP firing analyses 


\section{BEHAVIORAL ANALYSIS}

\section{Housing conditions}

421 Experiments were conducted blind for the genotypes in P71-87 male Emx1-cKO and Chat-cKO mice and

422 their respective Emx1-Cre ${ }^{-/}$and Chat-Cre ${ }^{-/}$control littermates. We used males and not female mice 423 because the ambulatory activity of females is impacted by the estrous cycle phases in rodents ${ }^{75}$ and may 424 bias the results of repetitive behavior measures that are partly dependent on motor activity.

$425 \quad$ Mice used in studies on social behavior are generally reared in groups of variable size and more 426 rarely in isolation. The choice of our rearing strategy was based on the fact that the measures of social 427 behavior in adult mice depends on the characteristics of the previous interactions that the observed male 428 has experienced with its peers ${ }^{3,76-78}$. In the rearing in group strategy, the social behaviors directed towards 429 the tested male can vary according to the genotypes, the androgen levels and the neurotransmitter profiles 430 of the individuals in the groups ${ }^{79}$. Consequently, the social behavior measured in an individual is the 431 resultant of the individual social ability plus a component corresponding to the interactions of the individual 432 with the other members of the group; this effect varies with the size of the group. In addition, behavioral 433 "contamination" resulting in an impairment of sociability in wild-type mice by cohabitant KO modeling ASD 434 was described ${ }^{78}$. Such undesirable effect plus the heterogeneity of the measures in mice reared in group 435 should contribute to avoid this strategy for testing social behavior. On the other hand, maintaining the mice 436 socially deprived generates a specific set of agonistic reactions that prevents the measures of social 437 abilities. To circumvent such biases, we have developed an alternative solution for years: each tested male 438 is housed with one female mouse belonging to a single inbred strain ${ }^{79}$. Here, a cKO or a control male mouse 439 was reared and maintained with $\mathrm{CBA} / \mathrm{H} / \mathrm{Gnc}$ female mice ${ }^{3}$. Housing was done in transparent $35 \times 20 \times 18$ $440 \mathrm{~cm}$ cages with 1-liter poplar woodchip bedding and weekly renewed enrichment (cardboard shelter). The 441 light (07:00-19:00) was 60 lux on the ground of the cages. The temperature was $21.5 \pm 0.5^{\circ} \mathrm{C}$. Behavioral 442 tests were performed in a dedicated room, the housing cage having been transferred one hour before the 443 beginning of the observations.

\section{Assessment of sensory function}

446 Visual, auditory and olfactory integrity is required to ensure the validity of the behavioral data. These 447 sensorial capacities were tested according to previously described protocols ${ }^{3,10,12,80 .}$

448 Visual capacities. The mouse was raised, taken by the tail, and a thin stick was approached to its eyes, 449 without touching the vibrissae. Raising the head was scored 1 and grasping or trying to grasp the pen was 450 scored 2. The test was administered five times and the sum of the scores recorded. Swimming towards a 451 distant shelf in the Morris Water Maze provided an additional assessment of the visual abilities.

452 Auditory capacities were measured using the Preyer's response. It consists in a pinna twitching and going 453 flat backwards against the head as reaction to sound. It is correlated with the average evoked auditory 454 potential and can be considered as an indicator of auditory acuity ${ }^{81-83}$. Mice emit vocalizations (less than 
$45520 \mathrm{kHz}$ ) and ultrasounds (above $20 \mathrm{kHz}$ ) in the presence of a conspecific male. For this reason, we 456 evaluated the responses to stimulations in the ultrasound bandwidth ( $50 \pm 0.008 \mathrm{kHz}$ and $35 \pm 0.010 \mathrm{kHz}$ ) 457 using commercial dog whistles. The mice received 5 stimulations with each sound. We scored 1 for ear 458 twitching and 2 for a pinna going flat backwards against the head.

459 Olfactory ability to detect an odor was evaluated by an increased time in sniffing a new odor using an 460 olfactory habituation/dishabituation test. Non-social aromas and social odors (urines from C57BL/6J and 461 SWR male mice) were presented individually to each mouse ${ }^{84}$. The trial was renewed the following day. 462 The individual score was the median time spent.

\section{ASD core features} Behaviors modeling the ASD domains as defined by DSM- 5 were assessed. The tests were selected based on their strong robustness (reliability from 0.77 to 0.92 ) and on their high loading scores in a factor analysis 3

Deficit in social behavior. A two-chamber test derived from Moy et al., $2004{ }^{85}$ was used to assess sociability and interest in social novelty. The setup and the protocol were detailed previously ${ }^{3,10,12}{ }^{\text {. We used a } 550 \mathrm{x}}$ $550 \mathrm{~mm}$ Plexiglas box split in a $150 \times 550 \mathrm{~mm}$ empty chamber and a $400 \times 550 \mathrm{~mm}$ chamber containing the two boxes ( $43 \mathrm{~mm}$ diameter, distant from $340 \mathrm{~mm}$ ) in which the mice or the lure were placed. Sociability is operationally defined as the higher number of visits towards the box containing a conspecific versus the one containing a lure (an adult mouse-sized oblong grey pebble), and the interest in social novelty as the higher number of visits towards a novel conspecific than towards the familiar one. Loss of social interest and poor interest in social novelty are expected in mice models of ASD. Briefly, the test consisted in a three-period observation, each lasting $10 \mathrm{~min}$ : 1) habituation (the two boxes containing lures), 2) sociability (one box containing a lure and the other a $\mathrm{C} 57 \mathrm{BL} / 6 \mathrm{~J}$ male) and 3) interest in social novelty (one box containing the same C57BL/6J and the other a new SWR male). The behaviors were video-recorded (Viewpoint-Behavior technologies) and the number of nose pokes towards the boxes was counted as measure of the number of visits ${ }^{86}$.

481 Repeated patterns of behavior. We selected four measures that were highly loaded on the "repetitive 482 patterns of behavior" factor in a factor analysis ${ }^{3}$ : marble burying and time burrowing in a new cage, number 483 of stereotyped dips in a hole-board device, and number of leanings in an open field. The protocols used 484 have been previously detailed ${ }^{3,10,12}$.The marble burying and time burrowing tests quantify perseverating 485 behavior ${ }^{87,88}$. Marble burying consists in scoring the amount of marbles buried by each mouse in a $30 \mathrm{~min}$ 486 session, using a $40 \times 18 \mathrm{~cm}$ cage with $45 \mathrm{~cm}$-thick litter and containing 20 marbles (9 mm diameter) on the surface of $70 \mathrm{~mm}$-thick dust-free sawdust. Completely buried, 2/3 buried and 1/2 buried marbles were scored 3, 2 and 1, respectively. The time burrowing test leans on spontaneous digging and pushing behavior that rodents display when placed into a new home cage. The length of time each mouse spent digging plus 490 pushing was measured. The number of stereotyped dips was counted in a hole-board device, consisting in 
491 a $40 \times 40 \mathrm{~cm}$ board with 16 equidistant holes $(3.5 \mathrm{~cm}$ diameter) each equipped with photo-beams for 492 detecting head dipping. Exploratory head dipping occurs when a rodent is placed on a surface with holes: 493 the mouse puts its head once into one hole of the board. Head dipping is considered stereotyped when the 494 head dips at least twice in the same hole within $2 \mathrm{~s}$. The open field behavior was measured in a circular 495 open field ( $100 \mathrm{~cm}$ diameter and $45 \mathrm{~cm}$ high walls) brightly lighted (210 lux on the ground). The ground was 496 virtually divided in three concentric zones of equal surface. The distances walked and the times spent in the 497 open field in the zones were automatically measured via the Viewpoint-Behavior technologies system 498 (http://www.viewpoint.fr/news.php). The observation lasted $20 \mathrm{~min}$. The number of leanings (rearing while 499 leaning) on the walls of the structure was previously validated as a measure of repetitive behavior ${ }^{3,89}$. The 500 number of zones crossed is a measure of the narrowness of the field of interest. The total distance walked 501 during the observation period served as covariate for the comparison between cKO mice and their 502 respective controls ${ }^{3}$.

\section{Additional behavioral measures}

Motor abnormalities and intellectual disability are not included among the ASD core features while having a noticeable but incomplete prevalence in ASD patients ( $\leq 79 \%$ and $\sim 45 \%$, respectively $\left.{ }^{58}\right)$. In this connection, two additional tests were conducted. Hind paw coordination. A mouse was first trained to cross a smooth bar $(50 \times 5 \times 5 \mathrm{~cm})$ with large platforms on each extremity. The trained mouse was then placed on the central platform $(3 \times 5 \mathrm{~cm})$ of a notched bar $(100 \mathrm{~cm})$ formed of $1.5 \mathrm{~cm}$ deep carvings regularly spaced $(2 \mathrm{~cm})$. The task consisted in ten bar crossings from the central to an extremity platform. The experimenters on each side of the setup counted the left and

513 Spatial learning. The Morris water maze provides measures of the ability of rodents to solve spatial learning 514 problems, namely the ability to find a submerged resting platform concealed beneath opaque water. The 515 platform is a glass cylinder ( $66 \mathrm{~mm}$ diameter, $9 \mathrm{~mm}$ beneath the surface of the water) positioned $23 \mathrm{~cm}$ from 516 the edge of a $100 \mathrm{~cm}$ diameter circular tank filled with water at $26 \pm 1^{\circ} \mathrm{C}$ and the light at 70 lux on the surface. 517 Each mouse performed 7 blocks of 4 trials each: one block on day 1, and two blocks daily (one in the 518 morning and one in the afternoon) for 3 successive days. A trial was stopped after $90 \mathrm{~s}$ if the mouse failed 519 to reach the platform. We considered that the mouse had reached the platform when it stayed on the 520 platform for $5 \mathrm{~s}$ at least. We presented a small metal shelf to the mouse $5 \mathrm{~cm}$ above the platform at the end 521 of each trial of the first block (shaping). The mouse climbed on it and was transferred in a cage with dry 522 sawdust for $120 \mathrm{~s}$. We had previously assigned 4 virtual cardinal points to the tank, each being the starting 523 point for a trial. The starting point for each trial was chosen randomly and within a block the mouse never 524 started more than once from the same virtual cardinal point. We measured 1) the time to reach the hidden 525 platform and 2) the cumulative distance to the center of the platform during swimming. The second measure 526 eliminates possible bias resulting from floating during the trial. The time to reach the platform and the 
527 distance were automatically measured by a video tracking setup (Viewpoint-Behavior technologies), each 528 over the 7 blocks. Strains can achieve different performance levels between blocks, but without a cumulative 529 reduction in the time to reach the platform, which is the criterion to identify learning process. We computed 530 the slopes of the learning curves, a negative slope indicating learning behavior ${ }^{91}$. The strategy was used 531 for both the time to reach the hidden platform and the cumulative distance to the center of the platform. The 532 probe-test procedure, conducted after removing the platform, was done $24 \mathrm{~h}$ after block 7 to meet the 533 requirements for reference memory ${ }^{92}$ and lasted $90 \mathrm{~s}$. The mouse was placed in the center of the tank, and

534 we measured the time of first crossing the virtual annulus corresponding to the location of the platform. To 535 check whether the differences in the time to reach the platform were due to vision and/or swimming abilities 536 rather than learning ability, we also tested groups of naïve Emx1-cKO and ChAT-cKO mice, and their 537 respective control, to the visible platform version of the test, in which the platform is $5 \mathrm{~mm}$ above non538 opacified water.

\section{STATISTICS}

542 Data were analyzed by Prism 7.05 (GraphPad Software, USA). Sample sizes, tests used, and $P$ values are reported in Figure legends. The significance threshold was set at $P<0.05$.

\section{RT-qPCR}

546 Statistical analysis for was performed by unpaired Student's $t$-tests using the qbasePLUS software version 2 (Biogazelle). The significance threshold was set at $P<0.05$.

\section{Electrophysiology}

550 Statistical analysis was performed by Prism 7.05 (GraphPad Software, USA). Student's $t$-test or two-tailed

551 Mann-Whitney test was used for comparing two data sets when passing or not D'Agostino \& Pearson's 552 normality test, respectively. Two-way ANOVA was used to analyze the influence of 2 categorical variables.

553 2-samples Kolmogorov-Smirnov test was used to compare cumulative distributions. Sample sizes (n) 554 reported in Figure legends refer to the number of recorded neurons. The significance threshold was set at $555 P<0.05$. Tests used, $P$ values and sample sizes are indicated in the Figure.

\section{Behavior}

558 Data were processed by Statistical Package for the Social Sciences [SPSS software, version $25{ }^{93}$ ]. The 559 same statistical designs were used to compare Emx1-cKO and ChAT-cKO mice to their respective controls. 560 Non-parametric statistics were chosen when the assumption of normality was rejected.

561 Impairment of social behavior. To analyze data from each social phase of the two-chamber test (sociability 562 and interest for social novelty), a mixed design analysis of covariance (ANCOVA) was used including the 
563 genotype as fixed factor, the box content as repeated measure, with measure of activity during habituation 564 as covariate. A significant interaction between genotype and box content indicates that social behavior 565 differs between the cKO and its control group.

566 Repetitive patterns of behavior and motor performance. The difference between two independent groups 567 (cKO and its control group) was tested by an unpaired two-sample Student's $t$-test in each case where it 568 was not necessary to include a covariate in the statistical design (i.e., stereotyped behavior: marble-burring 569 score, time burrowing, number of leanings; motor behavior: number of hind paw slips). For measures of 570 stereotyped dips, on which the activity level could have an impact, an analysis of covariance (ANCOVA) 571 was performed, using the genotype as fixed factor (cKO vs. respective control) and non-stereotyped dips 572 as covariate.

573 Sensorial abilities. Comparison of the visual and auditory capacities of the CKO and their respective controls 574 were conducted using a Student's $t$-test. Mixed repeated measures ANOVA, with genotype as fixed factor 575 and 15 odors as repeated measures, was used to compare cKO and their respective controls for olfactory 576 capacities.

577 Spatial learning. The statistical design was the same for the time to reach the platform and the cumulative

578 distance to the center of the platform in the Morris water maze test. Differences between the 7 blocks were 579 tested either with Friedman's ANOVA, a non-parametric version of one-way repeated measures ANOVA, 580 or with two-way repeated measures mixed ANOVA design, with blocks as repeated-measures variable and 581 cKO vs. control as between-group variable. Learning may be deduced from within-bloc statistical difference 582 and reduced time to reach the platform from one bloc to the next. The slope of the median values of the four 583 trials in each of the seven blocks was calculated for each mouse. The median slopes for the cKO and their 584 respective controls, as well as the time to reach the virtual platform (probe test) and the visible platform, 585 were compared with a Student's $t$-test

586 Effect size. Effect sizes are expressed as $\eta^{2}$ or as partial $\eta^{2}$ with $95 \%$ confidence interval ${ }^{93,94}$

\section{Ethic Statement}

590 The animal study was reviewed and approved by the "Comité National de Réflexion Ethique sur 591 l'Expérimentation Animale $n^{\circ} 14$ " and the project authorization delivered by the French Ministry of Higher 592 Education, Research and Innovation. (ID numbers 57-07112012, 2019020811238253-V2 \#19022 and 593 2020031615241974-V5 \#25232) and were in agreement with the European Communities Council Directive 594 (2010/63/EU).

595

\section{Acknowledgements}

597 Behavioral testing was performed at the mouse facility of the Marseille Medical Genetics (MMG) UMR1251

598 Aix Marseille Univ, INSERM. Microscopy was performed at the imaging platform of the IBDM and we 
599 acknowledge France-Biolmaging/PiCsL infrastructure (ANR-10-INSB-04-01). This work has received 600 support from the French government under the Programme "Investissements d'Avenir", Initiative 601 d'Excellence d'Aix-Marseille Université via A*Midex funding (NeuroMarseille Institute, AMX-19-IET-004; 602 MarMaRa Institute, AMX-19-IET-007), and ANR (ANR-17-EURE-0029). We wish to thank the IBDM mouse 603 facility.

604

\section{Funding}

606 This work was supported by the French National Research Agency (ANR) "TSHZ3inASD" project grant 607 nANR-17-CE16-0030-01 (to L.F. and L.K.-L.G.), the Fédération pour la Recherche sur le Cerveau (FRC) 608 (to L.F.), the Centre National de la Recherche Scientifique (CNRS) and Aix-Marseille University. D.C. and 609 J.M. were supported by PhD grants from the MESRI (Ministère de l'Enseignement Supérieur, de la 610 Recherche et de l'Innovation).

611

\section{Author Contribution}

613 X.C., J.M. and P.S. performed the histological experiments and the quantitative analyses; M.C. and P.L.R. 614 conducted the behavioral experiments and analyzed the resulting data; Y.B., L.B., J.M. and D.C. performed 615 patch-clamp experiments and P.G. analyzed electrophysiological data; M.M. performed dendritic spine 616 imaging and counting; A.F. performed RT-qPCR; X.C. and J.M. generated and maintained transgenic 617 mouse lines; X.C., L.F., P.G. and L.K.-L.G. conceived the project, supervised the work and wrote the paper 618 with the contribution of M.C. and P.L.R; all authors read and approved the final manuscript.

\section{Competing Financial Interest}

621 The authors declare no competing interests or potential conflicts of interest. 


\section{REFERENCES}

1. American Psychiatric Association. Diagnostic and Statistical Manual of Mental Disorders, DSM-5, Fifth Edition American Psychiatric Association: Washington, DC:, 2013.

2. Shuster J, Perry A, Bebko J, Toplak ME. Review of factor analytic studies examining symptoms of autism spectrum disorders. J Autism Dev Disord 2014; 44(1): 90-110.

3. Roubertoux PL, Tordjman S, Caubit X, di Cristopharo J, Ghata A, Fasano L et al. Construct Validity and Cross Validity of a Test Battery Modeling Autism Spectrum Disorder (ASD) in Mice. Behav Genet 2020; 50(1): 26-40.

4. Banerjee-Basu S, Packer A. SFARI Gene: an evolving database for the autism research community. Disease models \& mechanisms 2010; 3(3-4): 133-135.

5. Bourgeron T. Current knowledge on the genetics of autism and propositions for future research. CR Biol 2016; 339(7-8): 300-307.

6. Delmonte S, Gallagher L, O'Hanlon E, McGrath J, Balsters JH. Functional and structural connectivity of frontostriatal circuitry in Autism Spectrum Disorder. Front Hum Neurosci 2013; 7: 430.

7. Shepherd GM. Corticostriatal connectivity and its role in disease. Nature reviews: Neuroscience 2013; 14(4): 278-291.

8. Li W, Pozzo-Miller L. Dysfunction of the corticostriatal pathway in autism spectrum disorders. J Neurosci Res 2019.

9. Li M, Santpere G, Imamura Kawasawa Y, Evgrafov OV, Gulden FO, Pochareddy S et al. Integrative functional genomic analysis of human brain development and neuropsychiatric risks. Science 2018; 362(6420).

10. Caubit X, Gubellini P, Andrieux J, Roubertoux PL, Metwaly M, Jacq B et al. TSHZ3 deletion causes an autism syndrome and defects in cortical projection neurons. Nat Genet 2016; 48(11): 1359-1369.

11. Caubit X, Tiveron MC, Cremer H, Fasano L. Expression patterns of the three Teashirt-related genes define specific boundaries in the developing and postnatal mouse forebrain. J Comp Neurol 2005; 486(1): 76-88.

12. Chabbert D, Caubit X, Roubertoux PL, Carlier M, Habermann B, Jacq B et al. Postnatal Tshz3 Deletion Drives Altered Corticostriatal Function and Autism Spectrum Disorder-like Behavior. Biol Psychiatry 2019; 86(4): 274285.

13. Caubit X, Arbeille E, Chabbert D, Desprez F, Messak I, Fatmi A et al. Camk2a-Cre and Tshz3 expression in mouse striatal cholinergic interneurons: implications for autism spectrum disorder. Frontiers in Genetics in press; 12: 683959.

14. Munoz-Manchado AB, Bengtsson Gonzales C, Zeisel A, Munguba H, Bekkouche B, Skene NG et al. Diversity of Interneurons in the Dorsal Striatum Revealed by Single-Cell RNA Sequencing and PatchSeq. Cell Rep 2018; 24(8): 2179-2190 e2177.

15. Saunders A, Macosko EZ, Wysoker A, Goldman M, Krienen FM, de Rivera H et al. Molecular Diversity and Specializations among the Cells of the Adult Mouse Brain. Cell 2018; 174(4): 1015-1030 e1016.

16. Karvat $\mathrm{G}$, Kimchi T. Acetylcholine elevation relieves cognitive rigidity and social deficiency in a mouse model of autism. Neuropsychopharmacology 2014; 39(4): 831-840.

17. Rapanelli M, Frick LR, Xu M, Groman SM, Jindachomthong K, Tamamaki N et al. Targeted Interneuron Depletion in the Dorsal Striatum Produces Autism-like Behavioral Abnormalities in Male but Not Female Mice. Biol Psychiatry 2017; 82(3): 194-203.

18. Gorski JA, Talley T, Qiu M, Puelles L, Rubenstein JL, Jones KR. Cortical excitatory neurons and glia, but not GABAergic neurons, are produced in the Emx1-expressing lineage. J Neurosci 2002; 22(15): 6309-6314.

19. Dautan D, Huerta-Ocampo I, Witten IB, Deisseroth K, Bolam JP, Gerdjikov T et al. A major external source of cholinergic innervation of the striatum and nucleus accumbens originates in the brainstem. J Neurosci 2014; 34(13): 4509-4518.

20. Marin O, Anderson SA, Rubenstein JL. Origin and molecular specification of striatal interneurons. J Neurosci 2000; 20(16): 6063-6076.

21. Kawaguchi Y, Wilson CJ, Augood SJ, Emson PC. Striatal interneurones: chemical, physiological and morphological characterization. Trends Neurosci 1995; 18(12): 527-535. 
22. Bennett BD, Wilson CJ. Spontaneous activity of neostriatal cholinergic interneurons in vitro. J Neurosci 1999; 19(13): 5586-5596.

23. Bennett $\mathrm{BD}$, Callaway JC, Wilson $\mathrm{CJ}$. Intrinsic membrane properties underlying spontaneous tonic firing in neostriatal cholinergic interneurons. J Neurosci 2000; 20(22): 8493-8503.

24. Goldberg JA, Wilson CJ. The cholinergic interneurons of the striatum: intrinsic properties underlie multiple discharge patterns. In: Steiner H, Tseng KY (eds). Handbook of Basal Ganglia Structure and Function. Academic Press2010, pp 133-149.

25. Lozovaya N, Eftekhari S, Cloarec R, Gouty-Colomer LA, Dufour A, Riffault B et al. GABAergic inhibition in dualtransmission cholinergic and GABAergic striatal interneurons is abolished in Parkinson disease. Nat Commun 2018; 9(1): 1422.

26. Bicks LK, Koike H, Akbarian S, Morishita H. Prefrontal Cortex and Social Cognition in Mouse and Man. Front Psychol 2015; 6: 1805.

27. Chen P, Hong W. Neural Circuit Mechanisms of Social Behavior. Neuron 2018; 98(1): 16-30.

28. Fuccillo MV. Striatal Circuits as a Common Node for Autism Pathophysiology. Frontiers in neuroscience 2016; 10: 27.

29. Langen M, Schnack HG, Nederveen H, Bos D, Lahuis BE, de Jonge MV et al. Changes in the developmental trajectories of striatum in autism. Biol Psychiatry 2009; 66(4): 327-333.

30. Rapanelli M, Frick LR, Pittenger C. The Role of Interneurons in Autism and Tourette Syndrome. Trends in Neurosciences 2017.

31. Berretta N, Nistico R, Bernardi G, Mercuri NB. Synaptic plasticity in the basal ganglia: a similar code for physiological and pathological conditions. Progress in neurobiology 2008; 84(4): 343-362.

32. Lovinger DM. Neurotransmitter roles in synaptic modulation, plasticity and learning in the dorsal striatum. Neuropharmacology 2010; 58(7): 951-961.

33. Zhou JJ, Li DP, Chen SR, Luo Y, Pan HL. The alpha2delta-1-NMDA receptor coupling is essential for corticostriatal long-term potentiation and is involved in learning and memory. J Biol Chem 2018; 293(50): 19354-19364.

34. Park H, Popescu A, Poo MM. Essential role of presynaptic NMDA receptors in activity-dependent BDNF secretion and corticostriatal LTP. Neuron 2014; 84(5): 1009-1022.

35. Marotta R, Risoleo MC, Messina G, Parisi L, Carotenuto M, Vetri L et al. The Neurochemistry of Autism. Brain Sci 2020; 10(3).

36. Lee EJ, Choi SY, Kim E. NMDA receptor dysfunction in autism spectrum disorders. Curr Opin Pharmacol 2015; 20: 8-13.

37. Forrest MP, Parnell E, Penzes P. Dendritic structural plasticity and neuropsychiatric disease. Nat Rev Neurosci 2018; 19(4): 215-234.

38. Apicella P. The role of the intrinsic cholinergic system of the striatum: What have we learned from TAN recordings in behaving animals? Neuroscience 2017; 360: 81-94.

39. Tanimura A, Pancani T, Lim SAO, Tubert C, Melendez AE, Shen W et al. Striatal cholinergic interneurons and Parkinson's disease. Eur J Neurosci 2018; 47(10): 1148-1158.

40. Mallet N, Leblois A, Maurice N, Beurrier C. Striatal Cholinergic Interneurons: How to Elucidate Their Function in Health and Disease. Front Pharmacol 2019; 10: 1488.

41. Poppi LA, Ho-Nguyen KT, Shi A, Daut CT, Tischfield MA. Recurrent Implication of Striatal Cholinergic Interneurons in a Range of Neurodevelopmental, Neurodegenerative, and Neuropsychiatric Disorders. Cells 2021; 10(4).

42. Ahmed NY, Ranjbar-Slamloo Y, Al Abed AS, Gao L, Sontani Y, A RC-Hc-G et al. Er81 Transcription Factor FineTunes Striatal Cholinergic Interneuron Activity and Drives Habit Formation. J Neurosci 2021; 41(20): 4392-4409.

43. Gillan CM, Papmeyer M, Morein-Zamir S, Sahakian BJ, Fineberg NA, Robbins TW et al. Disruption in the balance between goal-directed behavior and habit learning in obsessive-compulsive disorder. Am J Psychiatry 2011; 168(7): 718-726.

44. Gonzales KK, Smith Y. Cholinergic interneurons in the dorsal and ventral striatum: anatomical and functional considerations in normal and diseased conditions. Ann NY Acad Sci 2015; 1349(1): 1-45.

45. Abudukeyoumu N, Hernandez-Flores T, Garcia-Munoz M, Arbuthnott GW. Cholinergic modulation of striatal microcircuits. Eur J Neurosci 2019; 49(5): 604-622. 
46. Martin-Ruiz CM, Lee M, Perry RH, Baumann M, Court JA, Perry EK. Molecular analysis of nicotinic receptor expression in autism. Brain Res Mol Brain Res 2004; 123(1-2): 81-90.

47. Perry EK, Lee ML, Martin-Ruiz CM, Court JA, Volsen SG, Merrit J et al. Cholinergic activity in autism: abnormalities in the cerebral cortex and basal forebrain. Am J Psychiatry 2001; 158(7): 1058-1066.

48. Deutsch SI, Urbano MR, Neumann SA, Burket JA, Katz E. Cholinergic abnormalities in autism: is there a rationale for selective nicotinic agonist interventions? Clin Neuropharmacol 2010; 33(3): 114-120.

49. Ragozzino ME, Mohler EG, Prior M, Palencia CA, Rozman S. Acetylcholine activity in selective striatal regions supports behavioral flexibility. Neurobiol Learn Mem 2009; 91(1): 13-22.

50. Eissa N, Azimullah S, Jayaprakash P, Jayaraj RL, Reiner D, Ojha SK et al. The dual-active histamine H3 receptor antagonist and acetylcholine esterase inhibitor E100 ameliorates stereotyped repetitive behavior and neuroinflammmation in sodium valproate induced autism in mice. Chem Biol Interact 2019; 312: 108775.

51. Martos YV, Braz BY, Beccaria JP, Murer MG, Belforte JE. Compulsive Social Behavior Emerges after Selective Ablation of Striatal Cholinergic Interneurons. J Neurosci 2017; 37(11): 2849-2858.

52. Crittenden JR, Lacey CJ, Weng FJ, Garrison CE, Gibson DJ, Lin Y et al. Striatal Cholinergic Interneurons Modulate Spike-Timing in Striosomes and Matrix by an Amphetamine-Sensitive Mechanism. Front Neuroanat 2017; 11: 20.

53. Murray RC, Logan MC, Horner KA. Striatal patch compartment lesions reduce stereotypy following repeated cocaine administration. Brain Res 2015; 1618: 286-298.

54. Aliane V, Perez S, Bohren Y, Deniau JM, Kemel ML. Key role of striatal cholinergic interneurons in processes leading to arrest of motor stereotypies. Brain 2011; 134(Pt 1): 110-118.

55. Ahmed NY, Knowles R, Dehorter N. New Insights Into Cholinergic Neuron Diversity. Front Mol Neurosci 2019; 12: 204.

56. Bariselli S, Fobbs WC, Creed MC, Kravitz AV. A competitive model for striatal action selection. Brain Res 2019; 1713: 70-79.

57. Goldberg JA, Ding JB, Surmeier DJ. Muscarinic modulation of striatal function and circuitry. Handb Exp Pharmacol 2012; (208): 223-241.

58. Lai MC, Lombardo MV, Baron-Cohen S. Autism. Lancet 2014; 383(9920): 896-910.

59. Xu M, Kobets A, Du JC, Lennington J, Li L, Banasr M et al. Targeted ablation of cholinergic interneurons in the dorsolateral striatum produces behavioral manifestations of Tourette syndrome. Proc Natl Acad Sci U S A 2015; 112(3): 893-898.

60. Blake MG, Boccia MM. Basal Forebrain Cholinergic System and Memory. Curr Top Behav Neurosci 2018; 37: 253-273.

61. Caubit X, Lye CM, Martin E, Core N, Long DA, Vola C et al. Teashirt 3 is necessary for ureteral smooth muscle differentiation downstream of SHH and BMP4. Development 2008; 135(19): 3301-3310.

62. Mao X, Fujiwara Y, Orkin SH. Improved reporter strain for monitoring Cre recombinase-mediated DNA excisions in mice. Proc Natl Acad Sci U S A 1999; 96(9): 5037-5042.

63. Madisen L, Zwingman TA, Sunkin SM, Oh SW, Zariwala HA, Gu H et al. A robust and high-throughput Cre reporting and characterization system for the whole mouse brain. Nat Neurosci 2010; 13(1): 133-140.

64. Rossi J, Balthasar N, Olson D, Scott M, Berglund E, Lee CE et al. Melanocortin-4 receptors expressed by cholinergic neurons regulate energy balance and glucose homeostasis. Cell Metab 2011; 13(2): 195-204.

65. Tamamaki N, Yanagawa Y, Tomioka R, Miyazaki J, Obata K, Kaneko T. Green fluorescent protein expression and colocalization with calretinin, parvalbumin, and somatostatin in the GAD67-GFP knock-in mouse. J Comp Neurol 2003; 467(1): 60-79.

66. Feng $\mathrm{G}$, Mellor $\mathrm{RH}$, Bernstein $\mathrm{M}$, Keller-Peck $\mathrm{C}$, Nguyen $\mathrm{QT}$, Wallace $\mathrm{M}$ et al. Imaging neuronal subsets in transgenic mice expressing multiple spectral variants of GFP. Neuron 2000; 28(1): 41-51.

67. Rodriguez A, Ehlenberger DB, Dickstein DL, Hof PR, Wearne SL. Automated three-dimensional detection and shape classification of dendritic spines from fluorescence microscopy images. PLoS One 2008; 3(4): e1997.

68. Chassain C, Melon C, Salin P, Vitale F, Couraud S, Durif F et al. Metabolic, synaptic and behavioral impact of 5week chronic deep brain stimulation in hemiparkinsonian rats. Journal of Neurochemistry 2016; 136(5): 10041016. 
69. Hattox AM, Nelson SB. Layer $\mathrm{V}$ neurons in mouse cortex projecting to different targets have distinct physiological properties. J Neurophysiol 2007; 98(6): 3330-3340.

70. Jiang ZG, North RA. Membrane properties and synaptic responses of rat striatal neurones in vitro. The Journal of physiology 1991; 443: 533-553.

71. Calabresi P, Maj R, Pisani A, Mercuri NB, Bernardi G. Long-term synaptic depression in the striatum: physiological and pharmacological characterization. J Neurosci 1992; 12(11): 4224-4233.

72. Calabresi P, Pisani A, Mercuri NB, Bernardi G. Long-Term Potentiation in the Striatum Is Unmasked by Removing the Voltage-Dependent Magnesium Block of Nmda Receptor Channels. Eur J Neurosci 1992; 4(10): 929-935.

73. Haghdoust $\mathrm{H}$, Janahmadi $\mathrm{M}$, Behzadi G. Physiological role of dendrotoxin-sensitive K+ channels in the rat cerebellar Purkinje neurons. Physiol Res 2007; 56(6): 807-813.

74. Maisano X, Litvina E, Tagliatela S, Aaron GB, Grabel LB, Naegele JR. Differentiation and functional incorporation of embryonic stem cell-derived GABAergic interneurons in the dentate gyrus of mice with temporal lobe epilepsy. J Neurosci 2012; 32(1): 46-61.

75. Beau Yon de Jonage-Canonico M, Roubertoux PL, Lenoir V, Carlier M, Kerdelhué B. Long-Term Reduction in Anxiety Levels During the Promotion Phase of Mammary Adenocarcinoma Induced by Dimethylbenz (a) Anthracene in Female Sprague-Dawley Rats. The Open Neuroendocrinol J 2010; 3: 52-58.

76. Ginsburg B, Allee W. Some effects of conditioning on social dominance and subordination in inbred strains of mice. Physiological Zoology 1942; 15(4): 485-506.

77. Maxson SC, Canastar A. Conceptual and methodological issues in the genetics of mouse agonistic behavior. Horm Behav 2003; 44(3): 258-262.

78. Kalbassi S, Bachmann SO, Cross E, Roberton VH, Baudouin SJ. Male and Female Mice Lacking Neuroligin-3 Modify the Behavior of Their Wild-Type Littermates. eNeuro 2017; 4(4).

79. Roubertoux PL, Guillot PV, Mortaud S, Pratte M, Jamon M, Cohen-Salmon C et al. Attack behaviors in mice: from factorial structure to quantitative trait loci mapping. Eur J Pharmacol 2005; 526(1-3): 172-185.

80. Roubertoux PL, Ghata A, Carlier M. Measuring Preweaning Sensorial and Motor Development in the Mouse. Curr Protoc Mouse Biol 2018; 8(1): 54-78.

81. Ehret G, Romand R. Development of tone response thresholds, latencies and tuning in the mouse inferior colliculus. Brain Res Dev Brain Res 1992; 67(2): 317-326.

82. Francis RL. The Preyer reflex audiogram of several rodents, and its relation to the "absolute" audiogram in the rat. J Aud Res 1979; 19(3): 217-233.

83. Willott JF. The Auditory Psychobiology of the Mouse. C.C. Thomas1983.

84. Yang M, Crawley JN. Simple behavioral assessment of mouse olfaction. Current protocols in neuroscience / editorial board, Jacqueline N Crawley [et al] 2009; Chapter 8: Unit 824.

85. Moy SS, Nadler JJ, Perez A, Barbaro RP, Johns JM, Magnuson TR et al. Sociability and preference for social novelty in five inbred strains: an approach to assess autistic-like behavior in mice. Genes, brain, and behavior 2004; 3(5): 287-302.

86. Roubertoux PL, Carlier M, Tordjman S. Organism Models of Autism Spectrum Disorders. Springer New York2015, 487pp.

87. Njung'e K, Handley SL. Effects of 5-HT uptake inhibitors, agonists and antagonists on the burying of harmless objects by mice; a putative test for anxiolytic agents. Br J Pharmacol 1991; 104(1): 105-112.

88. Thomas A, Burant A, Bui N, Graham D, Yuva-Paylor LA, Paylor R. Marble burying reflects a repetitive and perseverative behavior more than novelty-induced anxiety. Psychopharmacology (Berl) 2009; 204(2): 361-373.

89. Rizzo SJ. Repetitive Behavioral Assessments for Compound Screening in Mouse Models of Autism Spectrum Disorders. Methods Mol Biol 2016; 1438: 293-310.

90. Maarouf FD, Roubertoux PL, Carlier M. Is mitochondrial DNA involved in mouse behavioral laterality? Behav Genet 1999; 29(5): 311-318.

91. Roubertoux PL, Baril N, Cau P, Scajola C, Ghata A, Bartoli C et al. Differential Brain, Cognitive and Motor Profiles Associated with Partial Trisomy. Modeling Down Syndrome in Mice. Behav Genet 2017; 47(3): 305-322.

92. Alamed J, Wilcock DM, Diamond DM, Gordon MN, Morgan D. Two-day radial-arm water maze learning and memory task; robust resolution of amyloid-related memory deficits in transgenic mice. Nat Protoc 2006; 1(4): 1671-1679. 
bioRxiv preprint doi: https://doi.org/10.1101/2021.10.15.464549; this version posted October 15, 2021. The copyright holder for this preprint (which was not certified by peer review) is the author/funder. All rights reserved. No reuse allowed without permission.

824 93. Field AP. Discovering Statistics Using SPSS: (and Sex, Drugs and Rock'n'roll). SAGE2005.

825 94. Cohen J. Statistical power analysis for the behavioral sciences. 2nd edn. L. Erlbaum Associates: Hillsdale, N.J., 826 1988, xxi, 567 p.pp. 
bioRxiv preprint doi: https://doi.org/10.1101/2021.10.15.464549; this version posted October 15, 2021. The copyright holder for this preprint (which was not certified by peer review) is the author/funder. All rights reserved. No reuse allowed without permission.

a

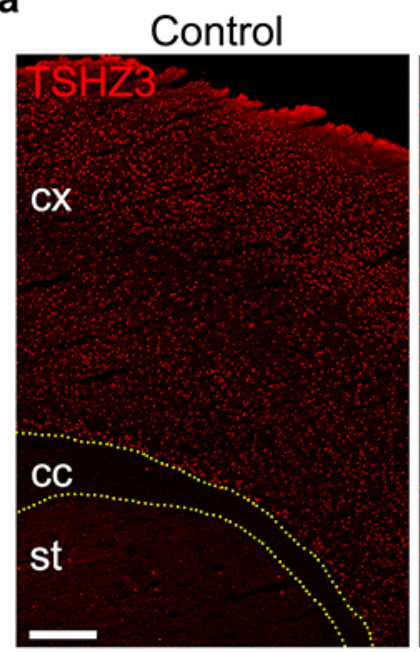

d

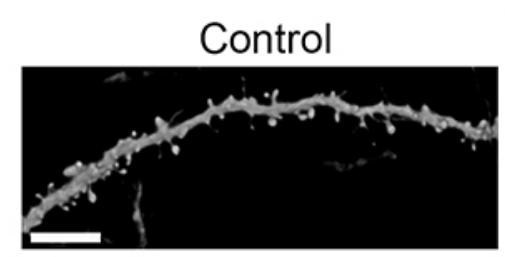

Emx1-cKO

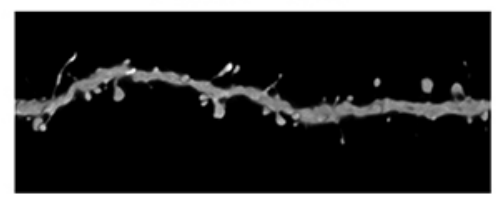

e

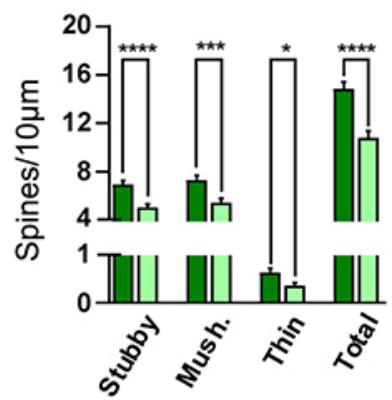

Emx1-cKO

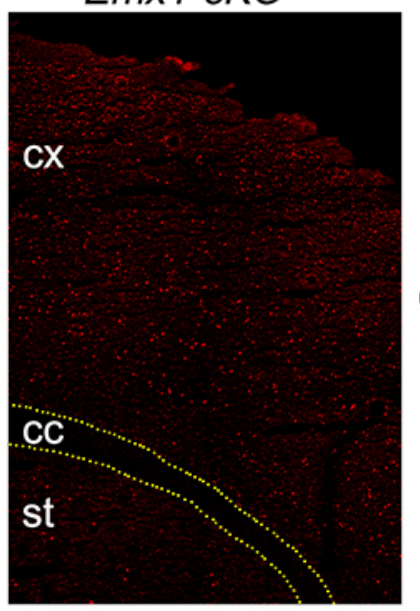

f

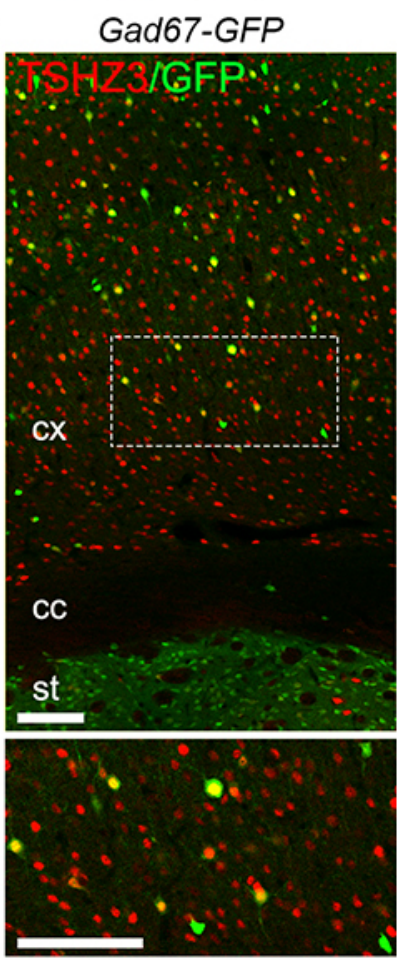

b

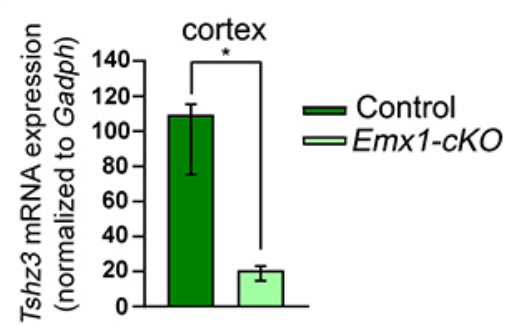

C

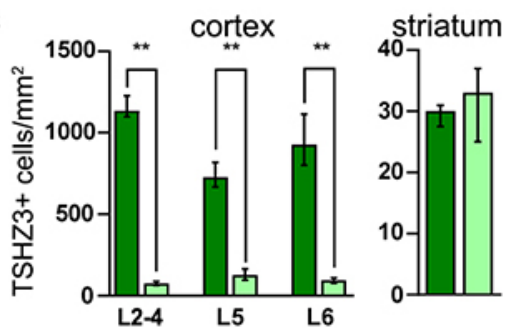

Emx1-cKO; Gad67-GFP

Figure 1. Conditional Tshz3 deletion in CPNs. a Coronal brain sections from control and Emx1-cKO mice immunostained for TSHZ3. Scale bar $250 \mu \mathrm{m}$. b Tshz3 mRNA relative expression in the cortex of control and Emx1-cKO mice measured by RT-qPCR (4 cortices per group; ${ }^{*} P<0.05$, Mann-Whitney test). c TSHZ3-positive cell density in control and Emx1-cKO mice in cortical layers (cell counts performed using frames of $400 \mu \mathrm{m}$ width spanning from L1 to L6 in 9 sections from 3 control mice and 18 sections from $3 E m \times 1-c K O$ mice; ${ }^{* *} P<0.01$, Mann-Whitney test) and in the whole striatal surface (cell counts performed in the whole dorsal striatum in 6 sections from 3 control mice and 7 sections from $3 E m \times 1-c K O$ mice; $P=0.1496$, Mann-Whitney test). d Representative confocal images showing dendritic spines of GFP-positive L5 neurons from control (Thy1-GFP-M) and Emx1-cKO (Thy1-GFP-M; $E m \times 1-c K O)$ mice. Scale bar $5 \mu \mathrm{m}$. e Density of different classes of dendritic spines in control (1688 spines/1135 $\mu \mathrm{m})$ and $E m \times 1-c K O(1308$ spines/1220 $\mu \mathrm{m})$ mice. $\mathrm{f}$ Coronal brain sections from GAD67GFP control and Emx1-cKO-GAD67-GFP mice immunostained for TSHZ3. Lower panels are magnifications of the framed areas in the upper images. Scale bars $100 \mu \mathrm{m}$. ${ }^{*} P<0.02,{ }^{* * *} P<0.001$ and ${ }_{* * * *} P<0.0001$, Student's $t$-test. Data in $\mathbf{b}$ and $\mathbf{c}$ are expressed as medians with interquartile range; data in $\mathbf{e}$ are expressed as means + SEM. 
bioRxiv preprint doi: https://doi.org/10.1101/2021.10.15.464549; this version posted October 15, 2021. The copyright holder for this preprint (which was not certified by peer review) is the author/funder. All rights reserved. No reuse allowed without permission.
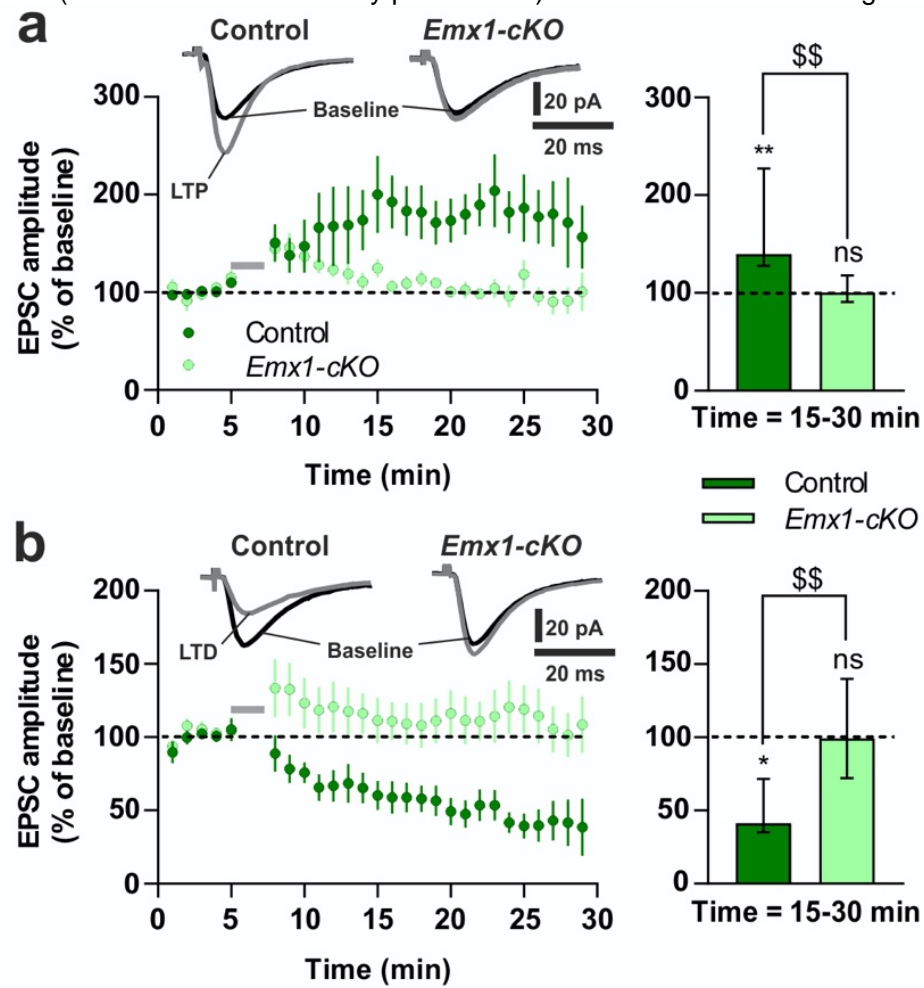

Figure 2. Impaired corticostriatal synaptic plasticity in Emx1-cKO mice. LTP a and LTD b are lost in Emx1-cKO mice. Left graphs: time-course (normalized EPSC amplitude expressed as means \pm SEM; grey bars represent induction protocols; 2-way ANOVA from 15 to $30 \mathrm{~min}$; LTP: $F(1,211)=44.8, P<$ 0.0001; LTD: $F(1,216)=153.2, P<0.0001)$. Traces show EPSCs before (black) and after (grey) LTP and LTD induction protocols. Right graphs: EPSC amplitude at 15-30 min (medians with interquartile range; Wilcoxon matched-pairs signed rank test vs. baseline: ${ }^{*} P<0.05,{ }^{* *} P<0.01$, ns $=$ non-significant; Mann-Whitney test: $\left.{ }^{\$} P<0.01\right)$. Data obtained from 17 SSPNs of control and 14 of Emx1-cKO mice. 
bioRxiv preprint doi: https://doi.org/10.1101/2021.10.15.464549; this version posted October 15, 2021. The copyright holder for this preprint (which was not certified by peer review) is the author/funder. All rights reserved. No reuse allowed without permission.

a

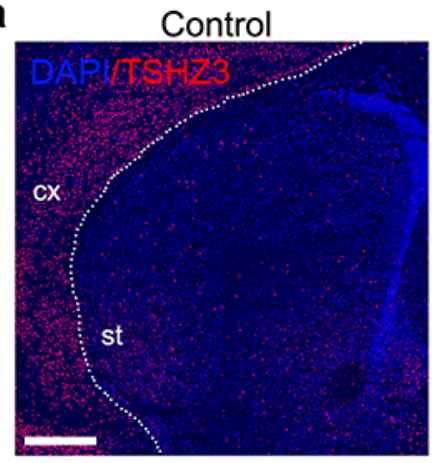

C

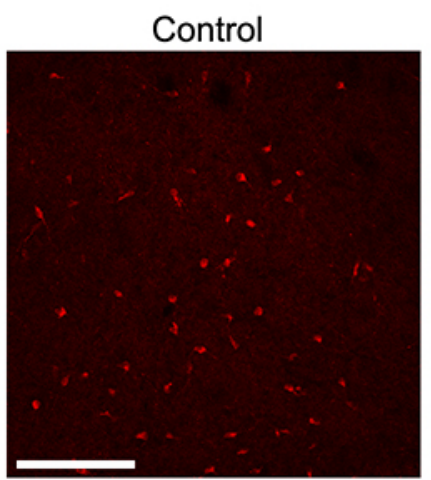

e

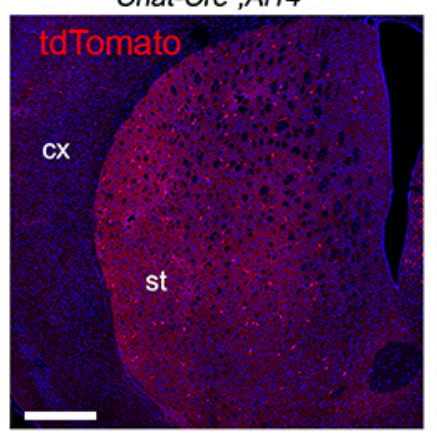

Chat-cKO

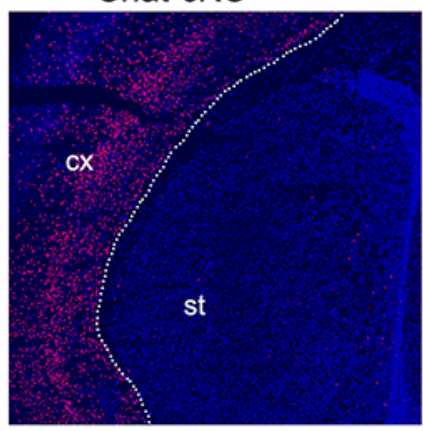

Chat-cKO

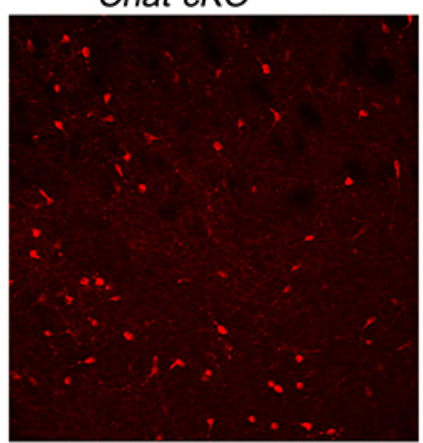

Chat-CKO;Ai14 Flox/+

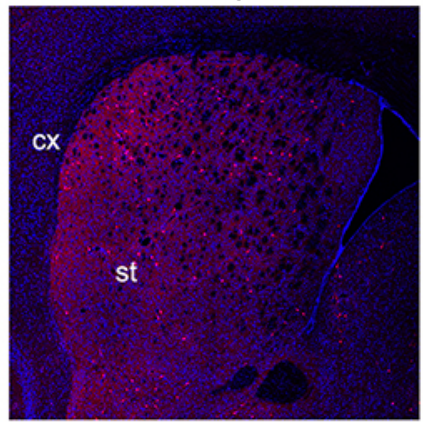

b

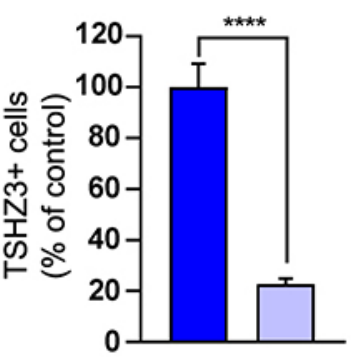

d

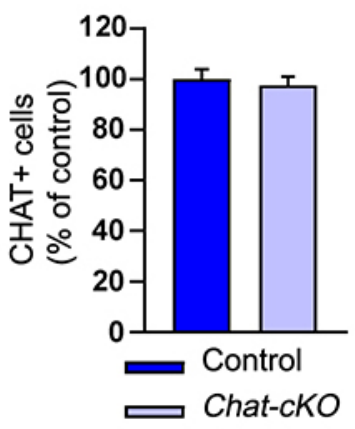

f

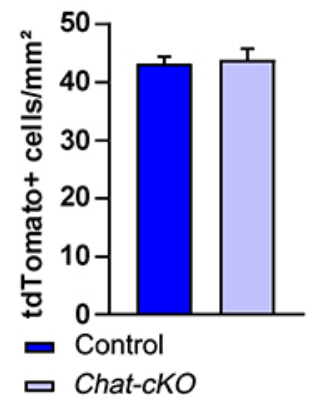

Figure 3. Conditional $T s h z 3$ deletion in cholinergic neurons. a Coronal brain sections from control and Chat-cKO mice immunostained for TSHZ3 and counterstained with DAPI. Scale bar $500 \mu \mathrm{m}$. b Number of TSHZ3-positive cells in the striatum of control and Chat-cKO mice; results are expressed as percent of mean control value ( 15 sections from 3 control mice; 11 sections from 3 Chat-cKO mice; ${ }^{* \star \star *} P$ $<0.0001$, Student's $t$-test). c Coronal brain sections from control and Chat-cKO mice stained for CHAT. Scale bar $200 \mu \mathrm{m}$. d Number of CHAT-positive SCINs in the striatum of control and Chat-cKO mice; results are expressed as percent of mean control value ( 40 sections from 9 control mice; 53 sections from 11 Chat-cKO mice; $P=0.6373$, Student's $t$-test). e Representative images showing tdTomato fluorescence detection (red) in SCINs of Chat-Cre;Ai14 ${ }^{\mathrm{Flox} /+}$ control and Chat-CKO;Ai14 ${ }^{\mathrm{Flox} /+}$ mutant mice (coronal sections). cx, cerebral cortex; st, striatum. Nuclei are counterstained with DAPI. Scale bar 500 $\mu \mathrm{m}$. $f$ Density of tdTomato-positive cells in the striatum of Chat-Cre;Ai14 ${ }^{\mathrm{Flox}+}$ control and ChatcKO;Ai14Flox/+ mutant mice (14 sections from 3 control mice; 12 sections from 3 Chat-cKO;Ai14Flox/+ mice; $P=0.6777$, Student's $t$-test). Data in $\mathbf{b}, \mathbf{d}$ and $\mathbf{f}$ are expressed as means + SEM. 
bioRxiv preprint doi: https://doi.org/10.1101/2021.10.15.464549; this version posted October 15, 2021. The copyright holder for this preprint

a (which was not certified by peer review) is the author/funder. All rights reserved. No reuse allowed without permission.

d

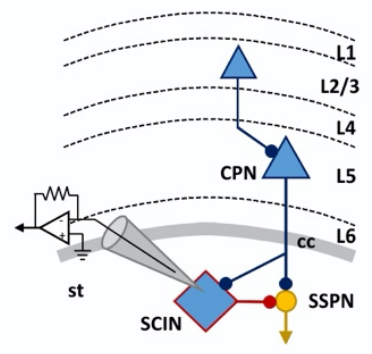

b

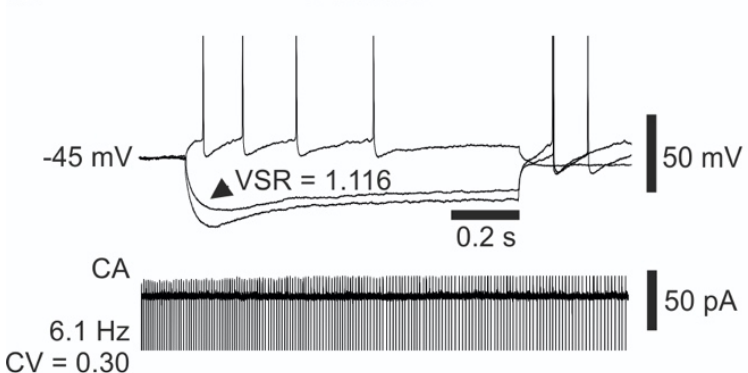

$\mathrm{CV}=0.30$

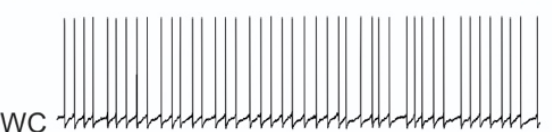

$5 \mathrm{~s}$

C
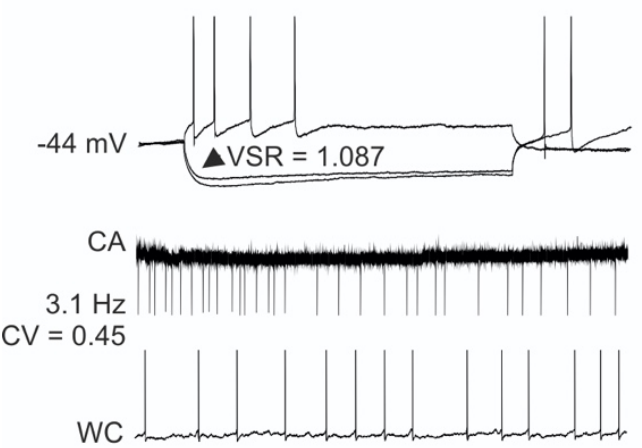

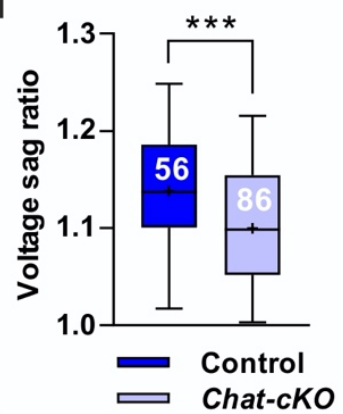

e

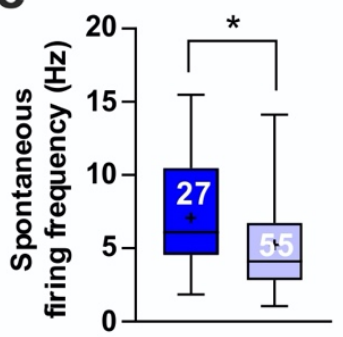

f

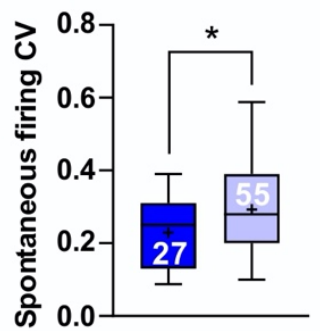

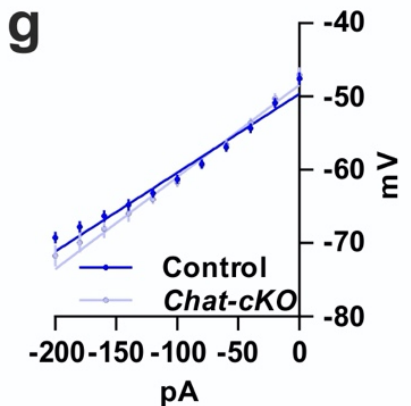

Figure 4. Altered electrophysiological properties of SCINs in Chat-cKO mice. a Simplified scheme of the corticostriatal circuitry with the recording patch-clamp pipette placed on a SCIN. TSHZ3expressing neurons are blue (L1-6, cortical layers 1-6; cc, corpus callosum; st, striatum). b Sample traces obtained from a representative control SCIN: note the prominent voltage sag in response to -200 and $-120 \mathrm{pA}$ hyperpolarizing currents, and the AP firing during a $+100 \mathrm{pA}$ depolarizing current ( $1^{\text {st }}$ line), as well as the sustained and regular firing in cell-attached (CA) and whole-cell (WC) configuration $\left(2^{\text {nd }}\right.$ and $3^{\text {rd }}$ line, respectively). c Sample traces obtained from a representative Chat-cKO SCIN: compared to $\mathbf{b}$, note the smaller voltage sag as well as the less regular, lower frequency spontaneous firing. (b, c) The values of voltage sag ratio (VSR) of the response to $-120 \mathrm{pA}$ current injection (arrowhead), as well as the frequency and coefficient of variation (CV) of spontaneous firing of these samples, are reported; spikes have been cut; calibration bars are the same in b and c. Compared to control, SCINs from ChatcKO mice show a significant reduction of mean voltage sag ratio (d) and frequency of spontaneous discharge e, while the $\mathrm{CV}$ of their inter-AP interval is increased (f) meaning that their spontaneous firing is more irregular. The number of recorded SCINs in d-f is reported in the graphs. g Current-voltage relationship obtained from 51 control and 62 Chat-cKO SCINs, and the linear best fit to calculate input resistance (see Results). ${ }^{*} P<0.05,{ }^{* * *} P<0.001$, Student's $t$-test; data in $\mathrm{d}$-f are expressed as box and whiskers (25th-75th and 5th-95th percentiles, respectively), where bar = median and cross = mean; data in $\mathrm{g}$ are expressed as means \pm SEM. 

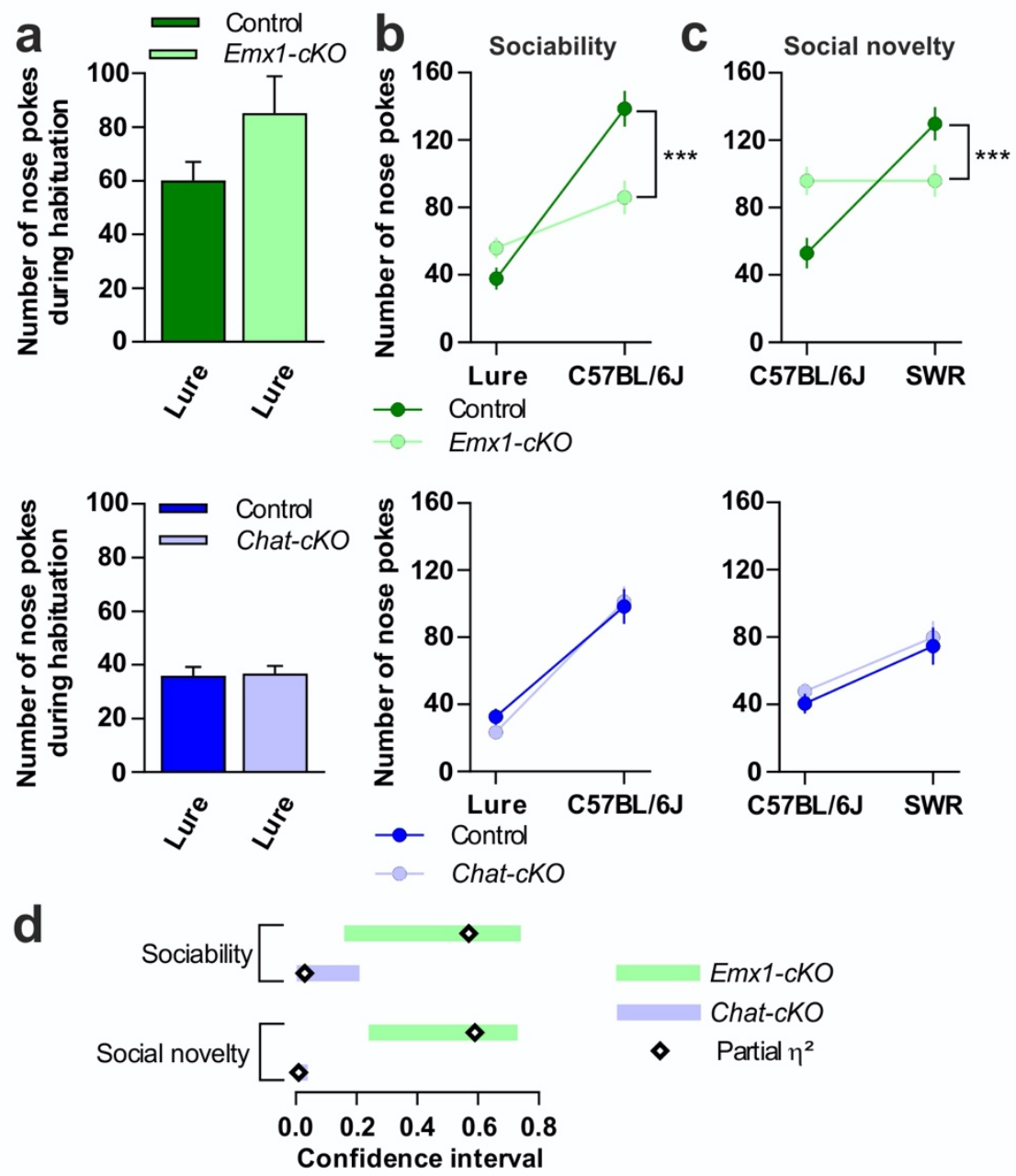

68

Figure 5. Sociability and social novelty deficits in Emx1-cKO but not in Chat-cKO mice. a Nose pokes during habituation, used as covariate for mixed-design ANCOVAs in $\mathbf{b}$ and $\mathbf{c}$. b Sociability measured as the number of nose pokes against a C57BL/6J male mouse or a lure. Emx1-cKO mice ( $\mathrm{n}$ = 9) vs. control $(n=8)$ : $F$ interaction $(1,14)=18.59, P<0.001$. Chat-cKO mice $(n=12)$ vs. control $(n=9)$ : $F_{\text {interaction }}(1,18)=0.55, P=0.47$. $\mathbf{c}$ Interest in social novelty measured as the number of nose pokes against the same C57BL/6J or a SWR mouse. Emx1-cKO vs. control: $F_{\text {interaction }}(1,14)=19.70, P<0.001$. Chat-cKO vs. control: $F_{\text {interaction }}(1,18)=0.02, P=0.89$. $\mathbf{d}$ Sizes of the difference for Emx1-cKO (partial $\eta^{2}=0.57$ and 0.59 for $\mathbf{b}$ and $\mathbf{c}$, respectively) and Chat-cKO mice (partial $\eta^{2}=0.03$ and 0.001 , respectively) vs. their respective control. Data in a-c are expressed as means \pm SEM. ${ }^{* * *} P<0.001$. 

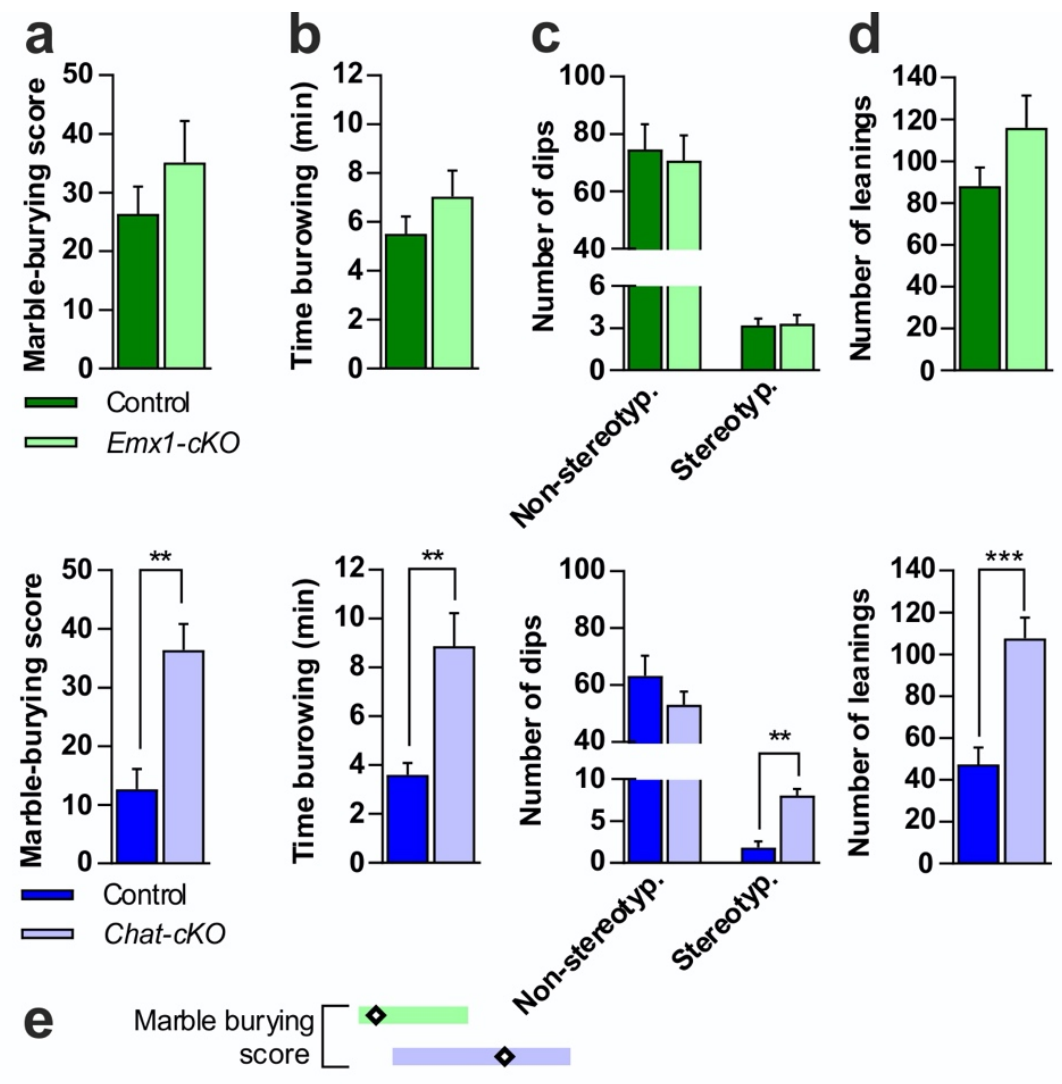

80

81

Figure 6. Repeated patterns of behavior in Chat-cKO but not in Emx1-cKO mice. a Marble-burying, $E m \times 1-c K O$, Student's-t(15) $=1.0, P=0.33$; Chat-cKO, $t(19)=3.97, P=0.001$. b Time burrowing, Emx1$c K O, t(15)=1.16, P=0.13) ;$ Chat-cKO, $t(19)=3.225, P=0.004$. c Stereotyped dips, Emx1-cKO, $F_{\text {interaction }}(1,15)=0.08, P=0.87$ (with non-stereotyped dips as covariate, $P=0.76$ ); Chat-cKO, $F_{\text {interaction }}(1,19)=32.69, P=0.00001$ (with non-stereotyped dips as covariate, $P=0.24$ ). $\mathbf{d}$ Number of leanings, $E m \times 1-c K O, t(15)=1.51, P=0.15$; Chat-cKO, $t(18)=4.35, P=0.0003$. e Sizes of the difference in $E m \times 1-c K O\left(\eta^{2}=0.06,0.08,0.13\right.$ in $a, b$ and d, respectively, and partial $\eta^{2}=0.01$ in $c$ ) and in Chat$c K O\left(\eta^{2}=0.45,0.35,0.51\right.$ in $\mathbf{a}, \mathbf{b}$ and $\mathbf{d}$, respectively, and partial $\eta^{2}=0.63$ in $\left.\mathbf{c}\right)$. Sample size of $\mathbf{a}, \mathbf{b}, \mathbf{c}$ and d were: 9, 9, 9 and 12 for Emx1-cKO; 8, 8, 9 and 11 for their controls; 12, 12, 12 and 11 for ChatcKO; $9,9,11$ and 8 for their controls. Data in a-d are expressed as means + SEM. ${ }^{* *} P<0.01{ }^{* * *} P<$ 0.001 . 
bioRxiv preprint doi: https://doi.org/10.1101/2021.10.15.464549; this version posted October 15, 2021. The copyright holder for this preprint (which was not certified by peer review) is the author/funder. All rights reserved. No reuse allowed without permission.
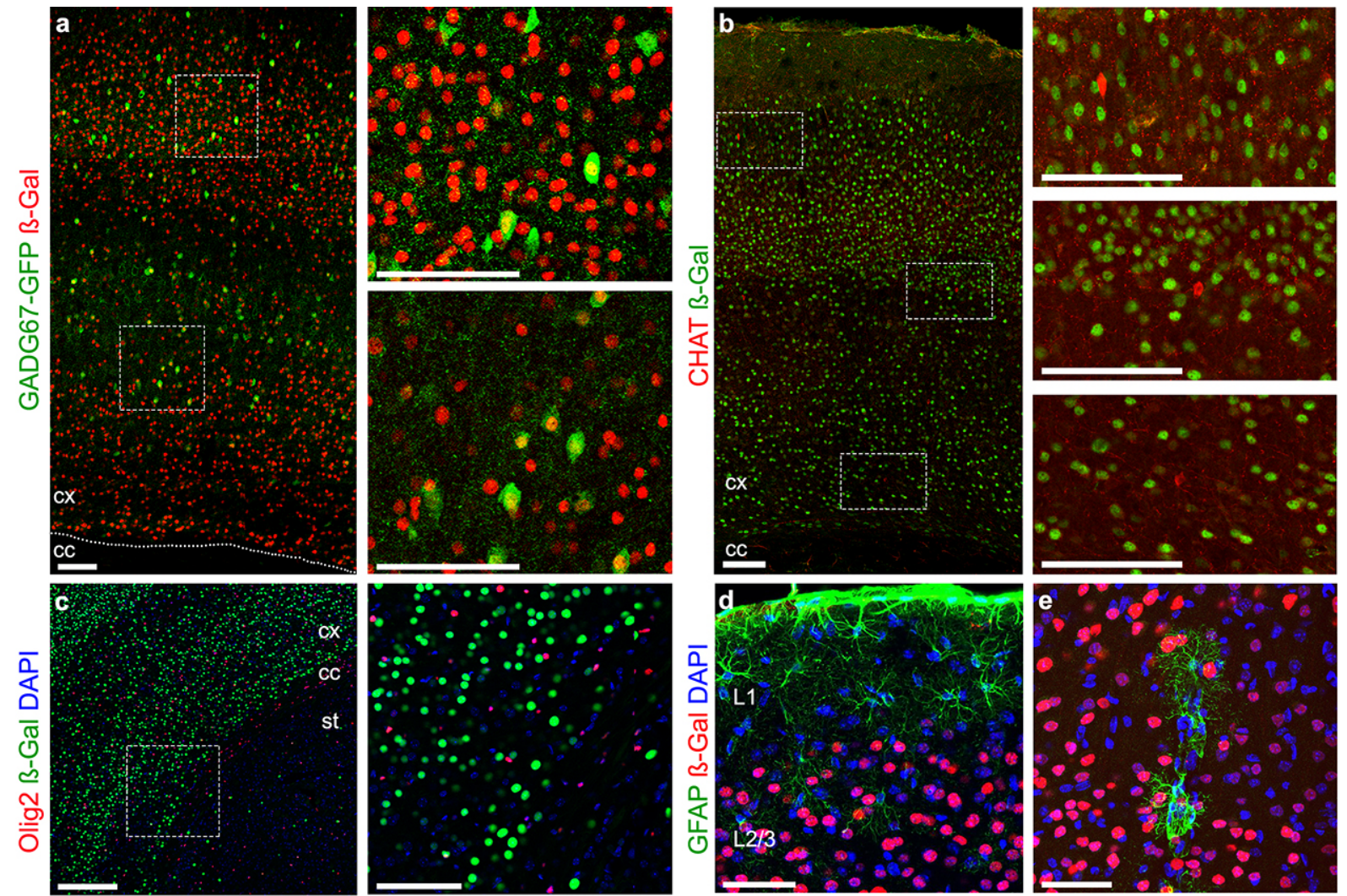

Figure S1. TSHZ3 expression in interneurons and glial cells in the cerebral cortex. (a-e) Coronal brain sections. a Tshz3 expression as $\beta-G a l$ staining in Tshz3+/lacz; GAD67-GFP mouse brain. The two images on the right are magnifications of the framed areas in A. Scale bars $100 \mu \mathrm{m}$. b Double immufluorescence staining for $\beta$-Gal and CHAT. The framed areas in (b) are magnified on the right. Scale bars $100 \mu \mathrm{m}$. c Double immufluorescence staining for Olig2 and B-Gal (left) and detail of the framed area (right). Scale bars $100 \mu \mathrm{m}$. (d, e) Double immufluorescence staining for GFAP and B-Gal.

10 Scale bars $100 \mu \mathrm{m}$ (d) and $50 \mu \mathrm{m}$ (e). Nuclei in c-e are counterstained with DAPI. cc, corpus callosum; cx, cerebral cortex; st, striatum. 
bioRxiv preprint doi: https://doi.org/10.1101/2021.10.15.464549; this version posted October 15, 2021. The copyright holder for this preprint (which was not certified by peer review) is the author/funder. All rights reserved. No reuse allowed without permission.

a control

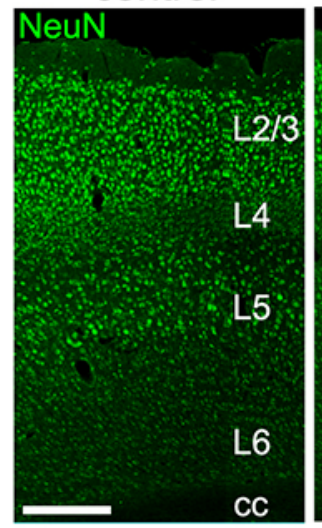

C

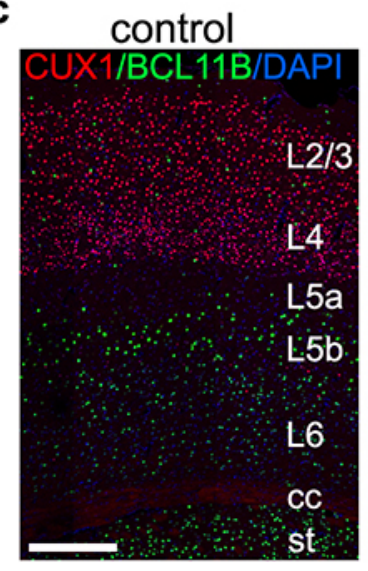

Emx1-cKO

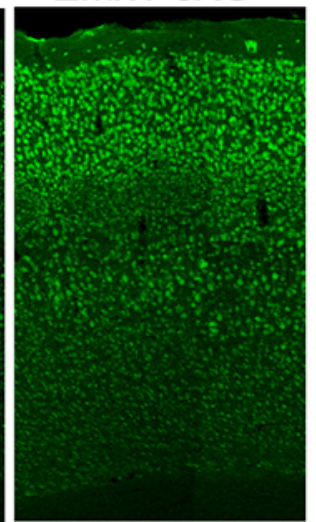

Emx1-cKO

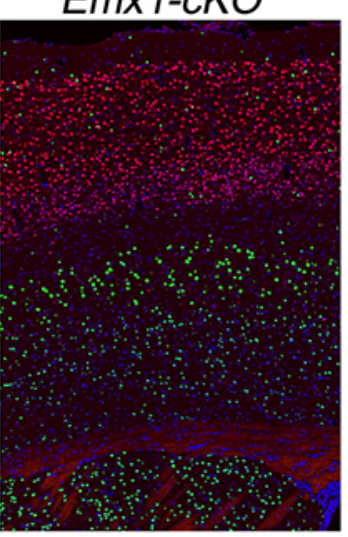

b

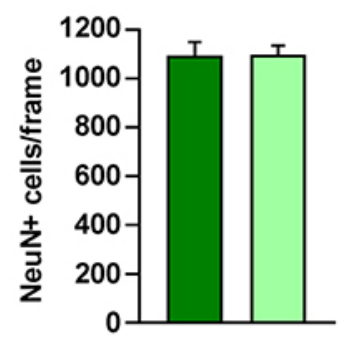

Control $\left(E m \times 1-\mathrm{Cre}^{-/}\right)$

एEmx1-cKO

d

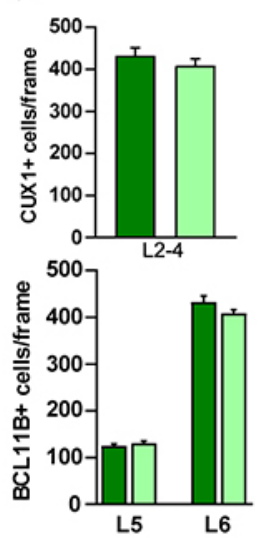

Figure S2. Cortical layering is preserved in Emx1-cKO mouse brain. a Coronal brain sections from Emx1-cKO and control mice immunostained for NeuN detection. Scale bar $250 \mu \mathrm{m}$. b Number of NeuNpositive cells counted in frames of $400 \mu \mathrm{m}$ width spanning the entire cortical thickness of control and $E m \times 1-c K O$ mice. No genotype difference is found (11 sections from 3 mice per genotype; $P=0.9488$, Student's $t$-test). c Coronal brain sections from Emx1-cKO and control mice immunostained for CUX1 and BCL11B. Nuclei are counterstained with DAPI. Scale bar $100 \mu \mathrm{m} ; \mathrm{cc}$, corpus callosum; st, striatum; L, layer. $\mathbf{d}$ Number of CUX1-positive cells in L2-4 and of BCL11B-positive cells in L5 and L6 in control and Emx1-cKO mice. No genotype difference is found (BCL11B-positive cells: 14 sections from 3 control mice and 18 sections from 3 Emx1-cKO mice; CUX1-positive cells: 28 sections from 4 control mice and 21 sections from 4 Emx1-cKO mice; countings were performed in cortical frames of $400 \mu \mathrm{m}$ width; $P=$ 0.3207 (L2/3), $P=0.4007$ (L5) and $P=0.1180$ (L6), Student's $t$-test). Data are expressed as means + SEM. 
bioRxiv preprint doi: https://doi.org/10.1101/2021.10.15.464549; this version posted October 15, 2021. The copyright holder for this preprint (which was not certified by peer review) is the author/funder. All rights reserved. No reuse allowed without permission.

a

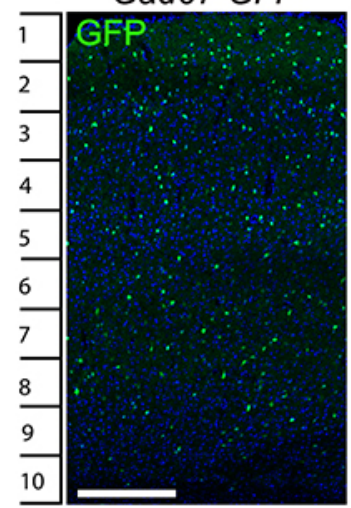

C

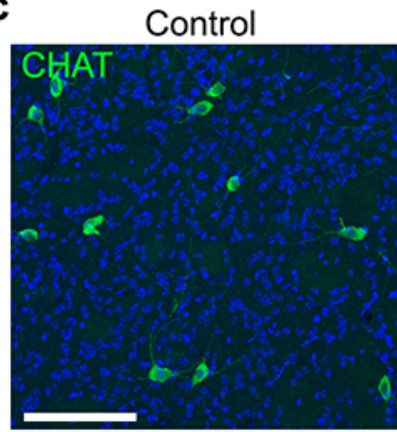

Emx1-CKO;Gad67-GFP b

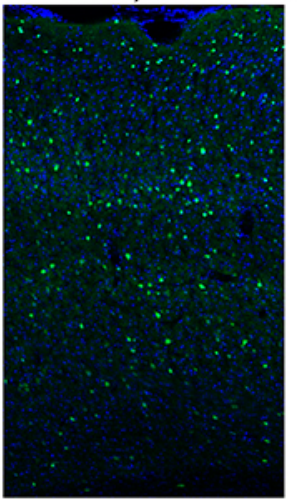

Emx1-cKO
Bin

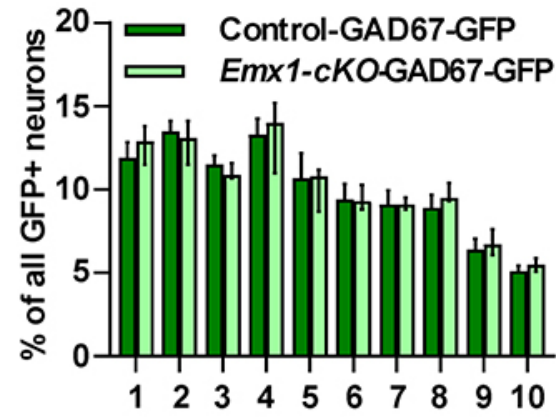

d
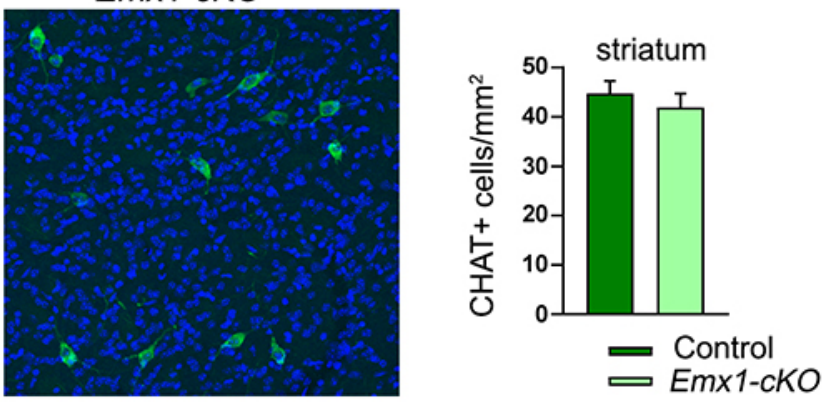

Figure S3. Loss of Tshz3 in Emx1-cKO mice does not affect the numbers of cortical GABAergic and striatal cholinergic interneurons. Representative images a and quantitative analysis $\mathbf{b}$ showing the distribution of GAD67-GFP-positive cells in the cerebral cortex in coronal brain sections from GAD67-GFP control and Emx1-cKO-GAD67-GFP mice. Scale bar in A $250 \mu \mathrm{m}$. Data in b are expressed as percent of total GFP-positive cells per bin (37 sections from 5 control mice; 41 sections from 7 Emx1$c K O$ mice; $F_{\text {genotype }}(1,100)=0.00006, P=0.994, F_{\text {interaction }}(9,100)=0.381, P=0.942,2$-way ANOVA). Images of CHAT immunostaining $\mathbf{c}$ and analysis of the density of CHAT-positive cells $\mathbf{d}$ in coronal brain sections at striatal level of control and Emx1-cKO mice. Scale bar $100 \mu \mathrm{m}$ (18 sections from 3 control and $3 E m \times 1-c K O$ mice, respectively; $P=0.465$, Student's $t$-test). Data in $\mathbf{b}$ are expressed as median with interquartile range; data in $\mathbf{d}$ as means + SEM. 
bioRxiv preprint doi: https://doi.org/10.1101/2021.10.15.464549; this version posted October 15, 2021. The copyright holder for this preprint

a (which was not certified by peer review) is the author/funder. All rights reserved. No reuse allowed without permission.

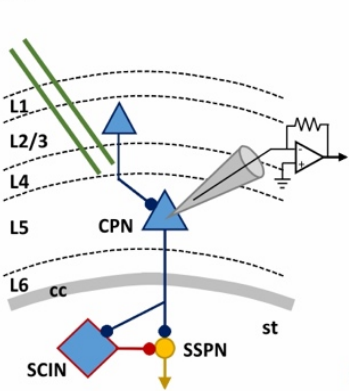

b

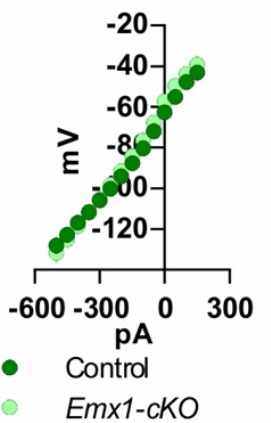

C

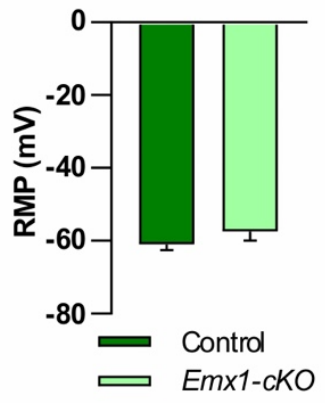

d

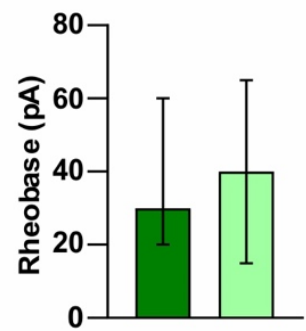

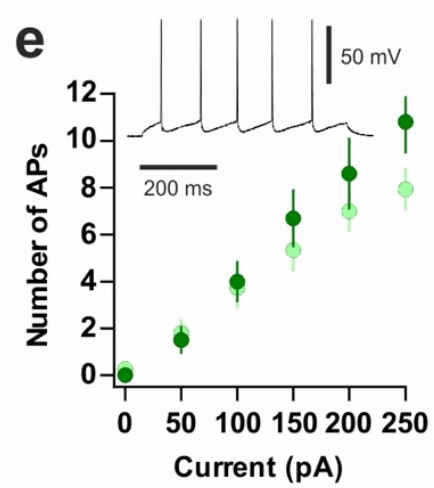
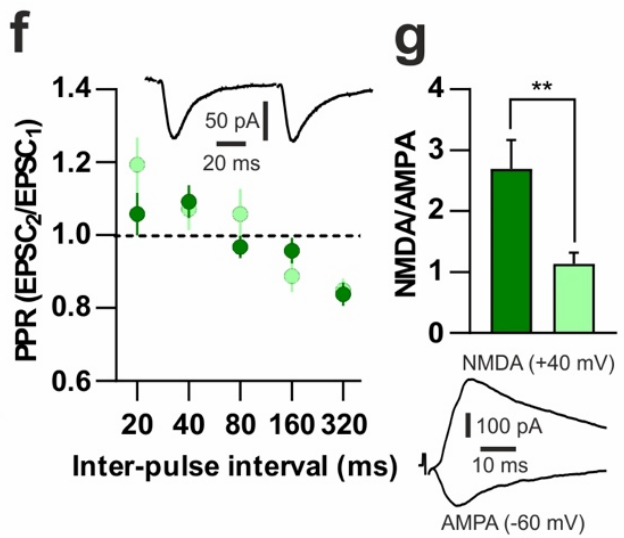

h
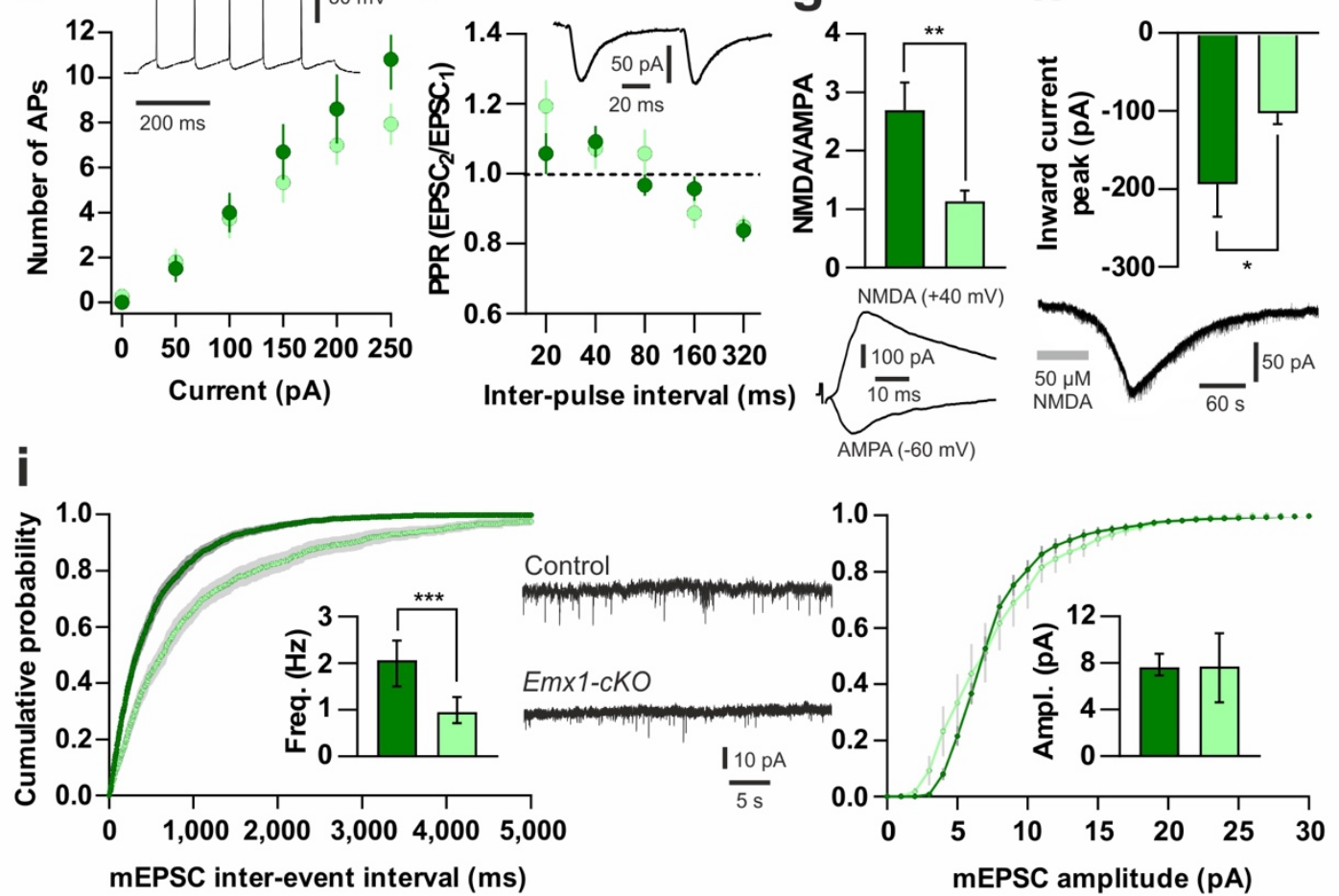

Figure S4. Electrophysiological characterization of L5 CPNs and basal cortical synaptic transmission. a Simplified scheme of the corticostriatal circuitry with the recording patch-clamp pipette placed on a L5 CPN and the stimulating electrode placed in L4. TSHZ3-expressing neurons are blue (L1-6, cortical layers 1-6; cc, corpus callosum; st, striatum). b Current-voltage relationship recorded from CPNs of Emx1-cKO mice and littermate controls show similar slopes and input resistance $(148.9 \pm 13.3$ vs. $151.3 \pm 11.6 \mathrm{M} \Omega$, respectively; $\mathrm{n}=21$ and $\mathrm{n}=28$, respectively; $P>0.05$, Student's $t$-test). c Resting membrane potential (RMP; $n=28-38)$ and $\mathbf{d}$ rheobase $(n=11-21)$ do not significantly differ between control and Emx1-cKO CPNs ( $P>0.05$ for both; Student's $t$-test and Mann-Whitney test, respectively). e The number of action potentials (APs) emitted by control $(n=10)$ and Emx1-cKO $(n=15)$ CPNs in response to increasing current injections is similar (2-way ANOVA: genotype $F(1,138)=3.068, P=$ 0.0821 ; interaction $F(5,138)=0.9349, P=0.4605$; multiple $t$-tests: $P>0.05)$. The trace shows an example of AP firing during a $100 \mathrm{pA}, 500$ ms current step. f Paired-pulse ratio (PPR) is not significantly different between control $(n=19)$ and $\operatorname{Emx1-cKO}(n=14)$ CPNs (2-way ANOVA: genotype $F(1,155)=$ 
bioRxiv preprint doi: https://doi.org/10.1101/2021.10.15.464549; this version posted October 15, 2021. The copyright holder for this preprint (which was not certified by peer review) is the author/funder. All rights reserved. No reuse allowed without permission. $0.901, P=0.344$; interaction $F(4,155)=1.431, P=0.2263)$. The trace shows an example of paired EPSCs (80 ms inter-pulse interval). $\mathbf{g}$ NMDA/AMPA ratio is significantly decreased in CPNs of Emx1$c K O$ mice compared to control ( $n=15$ for each genotype, ${ }^{* *} P<0.01$, Student's $t$-test). Traces show an example of a NMDA- and an AMPA receptor-mediated EPSC recorded from the same CPN at +40 and $-60 \mathrm{mV}$, respectively. $\mathbf{h}$ The tonic inward currents induced by bath application of NMDA ( $50 \mu \mathrm{M}, 60 \mathrm{~s})$ are significantly smaller in CPNs from Emx1-cKO mice compared to control $(n=15$ and $n=14$, respectively; ${ }^{*} P<0.05$, Student's $t$-test). The trace shows a sample response of a CPN (sEPSCs have been cut) to NMDA bath application (grey bar). $\mathbf{i}$ The distribution of mEPSC inter-event intervals is significantly different between control $(n=12)$ and Emx1-cKO $(n=11)$ CPNs $(P<0.0001,2$-samples Kolmogorov-Smirnov test), as well as their median frequency (inset) ${ }^{* * *} P<0.001$, Mann-Whitney test). Conversely, both the distribution and the median values of mEPSC amplitude are similar in control and Emx1-cKO CPNs ( $P>0.05$, 2-samples Kolmogorov-Smirnov test and Mann-Whitney test). Cumulative plots represent mean values (light and dark green) and SEM (grey). Traces show sample mEPSCs recorded from control and Emx1-cKO CPNs. Data in b, c, e-h and in $\mathbf{i}$ (cumulative plots) are expressed as means \pm SEM; data in $\mathbf{d}$ and in $\mathbf{i}$ (insets) are expressed as medians with interquartile range. 

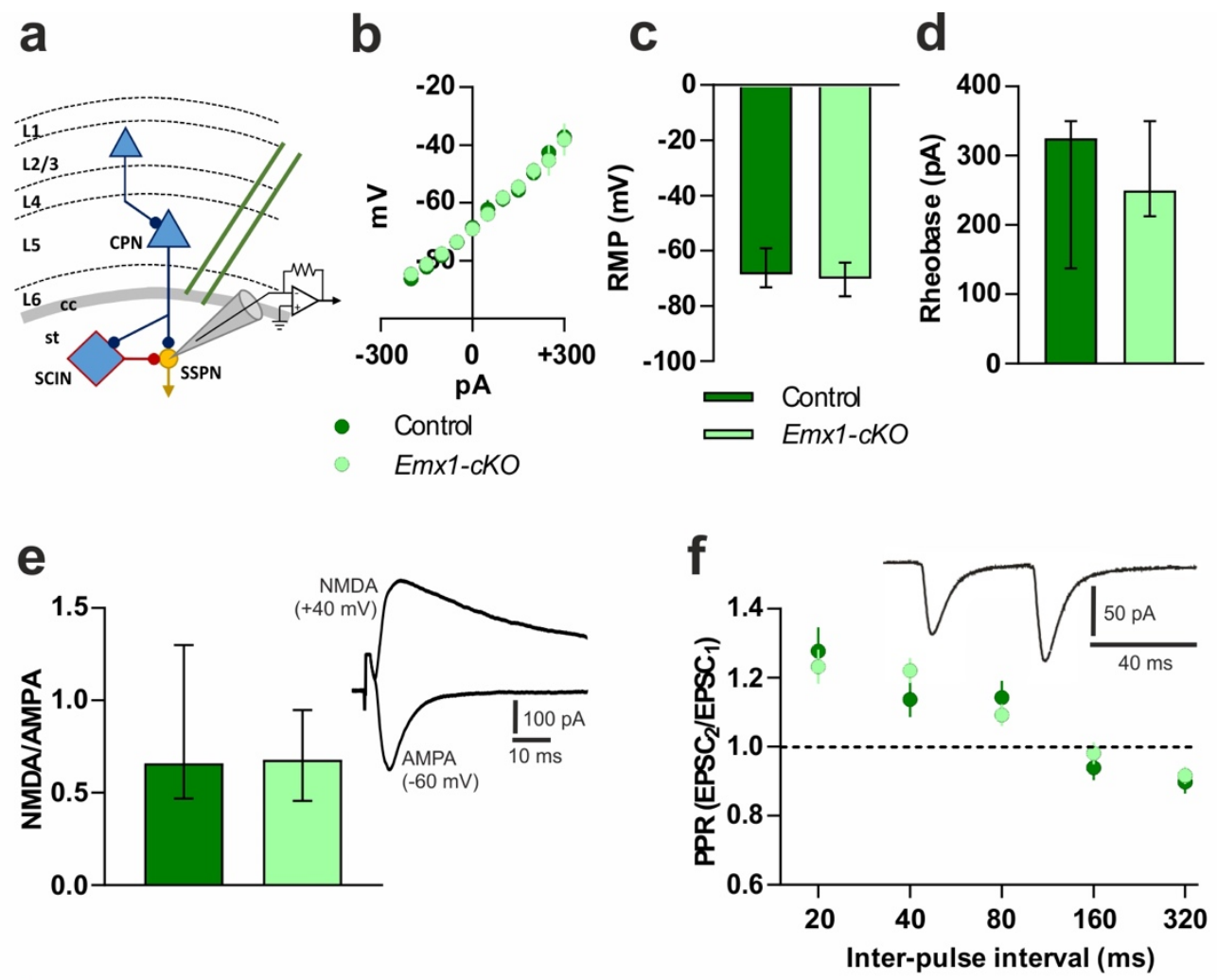

g

Figure S5. Electrophysiological characterization of SSPNs and basal corticostriatal synaptic transmission. a Simplified scheme of the corticostriatal circuitry with the recording patch-clamp pipette placed on a SSPN and the stimulating electrode placed on the cc. TSHZ3-expressing neurons are blue (L1-6, cortical layers 1-6; cc, corpus callosum; st, striatum). b Current-voltage relationship recorded from SSPNs of control and Emx1-cKO mice provide similar slopes and input resistance (97.4 \pm 2.3 vs. 93.0 $\pm 2.1 \mathrm{M} \Omega$, respectively; $\mathrm{n}=7$ and $\mathrm{n}=15$, respectively; $P=0.1862$, Mann-Whitney test). c Resting membrane potential (RMP) and $\mathbf{d}$ rheobase are not significantly different between control $(n=7)$ and Emx1-cKO $(\mathrm{n}=15)$ SSPNs $(P>0.05$, Mann-Whitney test). e NMDA/AMPA ratio is similar between control $(\mathrm{n}=11)$ and Emx1-cKO $(\mathrm{n}=12)$ SSPNs $(P>0.05$, Mann-Whitney test); traces in e show an example of an NMDA receptor- and an AMPA receptor-mediated EPSC recorded from the same SSPN at +40 and $-60 \mathrm{mV}$, respectively. $\mathbf{f}$ Paired-pulse ratio (PPR) is similar between control $(\mathrm{n}=18)$ and Emx1-cKO ( $\mathrm{n}=24)$ SSPNs (2-way ANOVA: genotype $F(1,162)=0.1135, P=0.7367$; interaction $F(4,162)=0.8429, P=0.4999)$. The trace shows an example of paired EPSCs (40 ms inter-pulse 
bioRxiv preprint doi: https://doi.org/10.1101/2021.10.15.464549; this version posted October 15, 2021. The copyright holder for this preprint (which was not certified by peer review) is the author/funder. All rights reserved. No reuse allowed without permission.

90 interval). $\mathbf{g}$ The distribution of mEPSC inter-event intervals is significantly different between control $(\mathrm{n}=$

91 8) and Emx1-CKO ( $\mathrm{n}=7)$ SSPNs $(P<0.001,2$-samples Kolmogorov-Smirnov test), but their median 92 frequency (inset) is similar $(P>0.05$, Mann-Whitney test). Both the distribution and the median value of 93 mEPSC amplitude are not significantly different between control and Emx1-cKO SSPNs $(P>0.05,2-$ 94 samples Kolmogorov-Smirnov test and Mann-Whitney test). Cumulative plots represent average values 95 (light and dark green) and SEM (grey). Traces show sample mEPSCs recorded from control and Emx1cKO SSPNs. Data in $\mathbf{b}, \mathbf{f}$ and $\mathbf{g}$ (cumulative plots) are expressed as means \pm SEM; data in $\mathbf{c}-\mathbf{e}$ and $\mathbf{g}$ insets are expressed as medians with interquartile range. 
bioRxiv preprint doi: https://doi.org/10.1101/2021.10.15.464549; this version posted October 15, 2021. The copyright holder for this preprint 99 (which was not certified by peer review) is the author/funder. All rights reserved. No reuse allowed without permission.

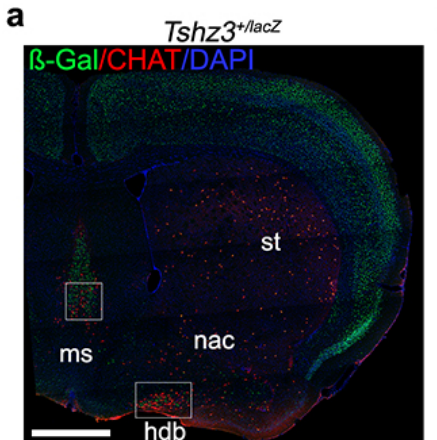

C
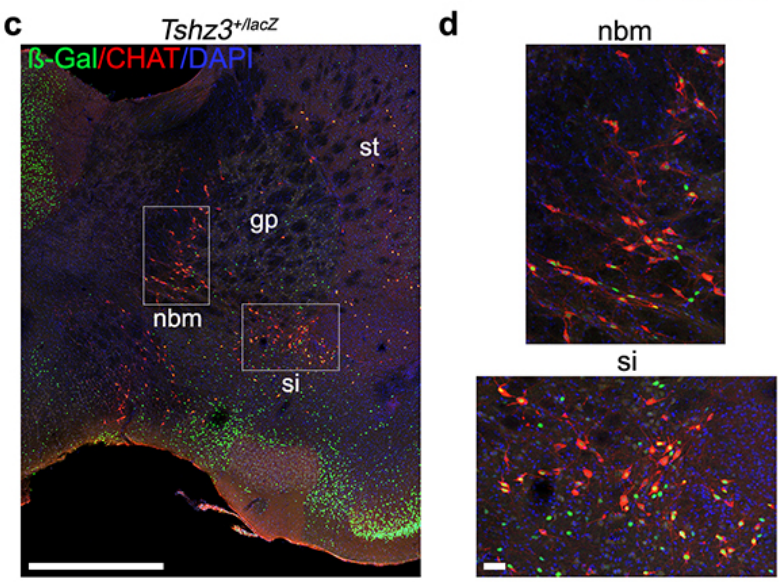
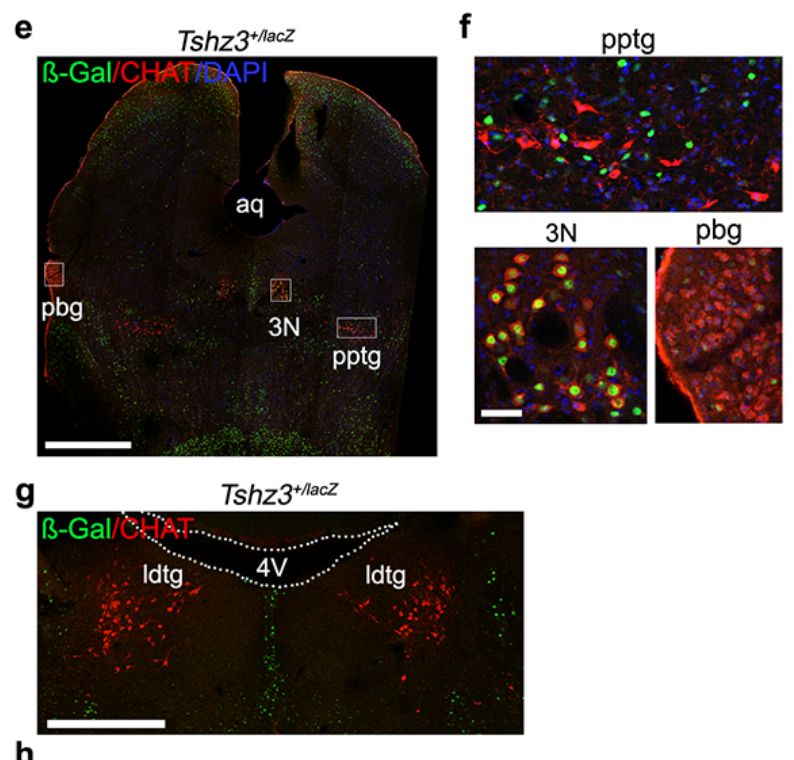

h

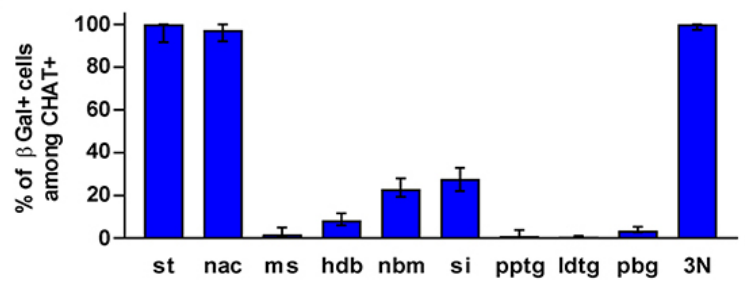

Fig. S6. TSHZ3 expression in the main brain cholinergic systems. Forebrain (a-d) and brainstem (e-g) coronal sections stained for $ß-G a l$ and CHAT. (b, d, f) Higher-power images of framed regions in

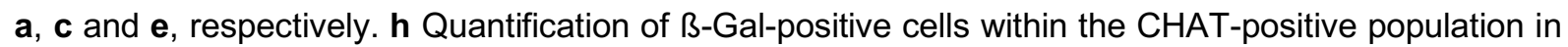
brain structures containing cholinergic neurons. aq, aqueduct; hdb, nucleus of the horizontal limb of the diagonal band; gp, globus pallidus; Idtg, laterodorsal tegmental nucleus; ms, medial septal nucleus; nac, nucleus accumbens; nbm, nucleus basalis of Meynert; pbg, parabigeminal nucleus; pptg, pedunculopontine tegmental nucleus; si, substantia innominata; st, striatum; $3 \mathrm{~N}$, oculomotor nucleus; $4 \mathrm{~V}, 4^{\text {th }}$ ventricle. Nuclei were counterstained with DAPI. Data are expressed as medians with interquartile range; they were obtained from 6 (3N), 7 (hdb), 9 (ms) 12 (pbg, si), 16 (Idtg), 17 (nac), 19 (st), 24 (pptg) and 40 (nbm) sections from 3 ( $\mathrm{hdb}, \mathrm{Idtg}, \mathrm{ms}$, pbg and pptg), 4 (si and 3N), 6 (nac), 7 (st) and $8(\mathrm{nbm})$ mice, respectively. 
bioRxiv preprint doi: https://doi.org/10.1101/2021.10.15.464549; this version posted October 15, 2021. The copyright holder for this preprint

a (which was not certified by peer review) is the author/funder. All rights reserved. No reuse allowed without permission.

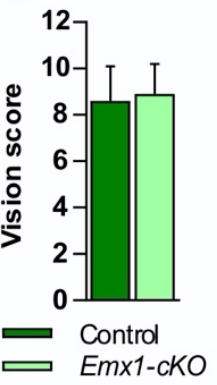

b
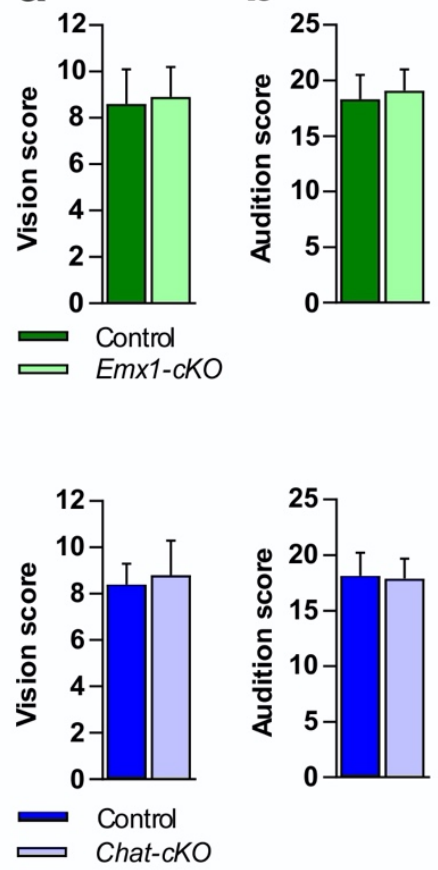

C
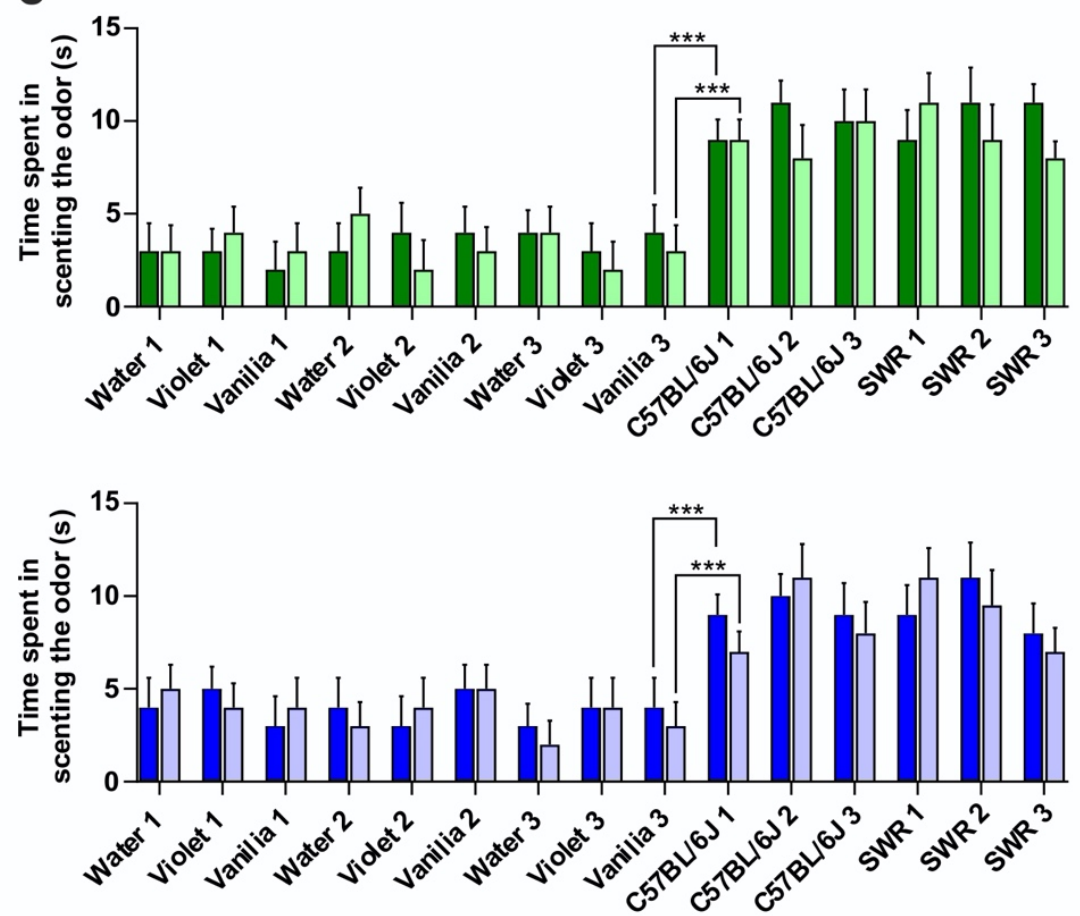

Figure S7. Visual, auditory and olfactory capacities in Emx1-cKO and Chat-cKO mice compared with their respective littermate controls. Ten mice per genotype were used in each screening. a Visual capacity differs neither in Emx1-cKO mice compared to their controls (Student's $t<1$, df $=18$, non-significant (NS)), nor in Chat-cKO compared to their controls (Student's $t<1$, df $=18, \mathrm{NS}$ ). b Auditory capacities differ neither in Emx1-cKO mice compared to their controls (Student's $t=1.2, \mathrm{df}=$ 18, NS), nor in Chat-cKO mice compared to their controls (Student's $t<1, \mathrm{df}=18, \mathrm{NS}$ ). c Time spent scenting non-social (water, violet, vanilla) and social (C57BL/6J, SWR) odors were analyzed with two mixed ANOVAs (Emx1-cKO and Chat-cKO vs. their respective control, and 15 odors as repeated measures). The genotype factor was not significant $(F<1, \mathrm{df}=1,18)$ in both cases. Emx1-cKO, Chat$c K O$ and their respective control spent more time sniffing social than non-social odors, as shown by comparing time sniffing vanilla $3 \mathrm{vs}$. C57BL/6J urine 1, the size of the differences being similar in each case for the $\mathrm{KO}$ and the control group $(E m \times 1-c K O$ and control littermate: paired Student's $t=4.5, \mathrm{df}=9$, and $t=3.78, \mathrm{df}=9$, respectively; $P<0.001$; sizes of the differences : $\eta^{2}=0.57$ and 0.51 , respectively; Chat-cKO and control littermate: paired Student's $t=5.7, \mathrm{df}=9$, and $t=4.9, \mathrm{df}=9$, respectively; $P<$ 0.001 ; sizes of the differences: $\eta^{2}=0.49$ and 0.40 , respectively). Data are expressed as means + SEM. ${ }^{* * *} P<0.001$. 
bioRxiv preprint doi: https://doi.org/10.1101/2021.10.15.464549; this version posted October 15, 2021. The copyright holder for this preprint (which was not certified by peer review) is the author/funder. All rights reserved. No reuse allowed without permission. Restricted field of interest Hind paw coordination
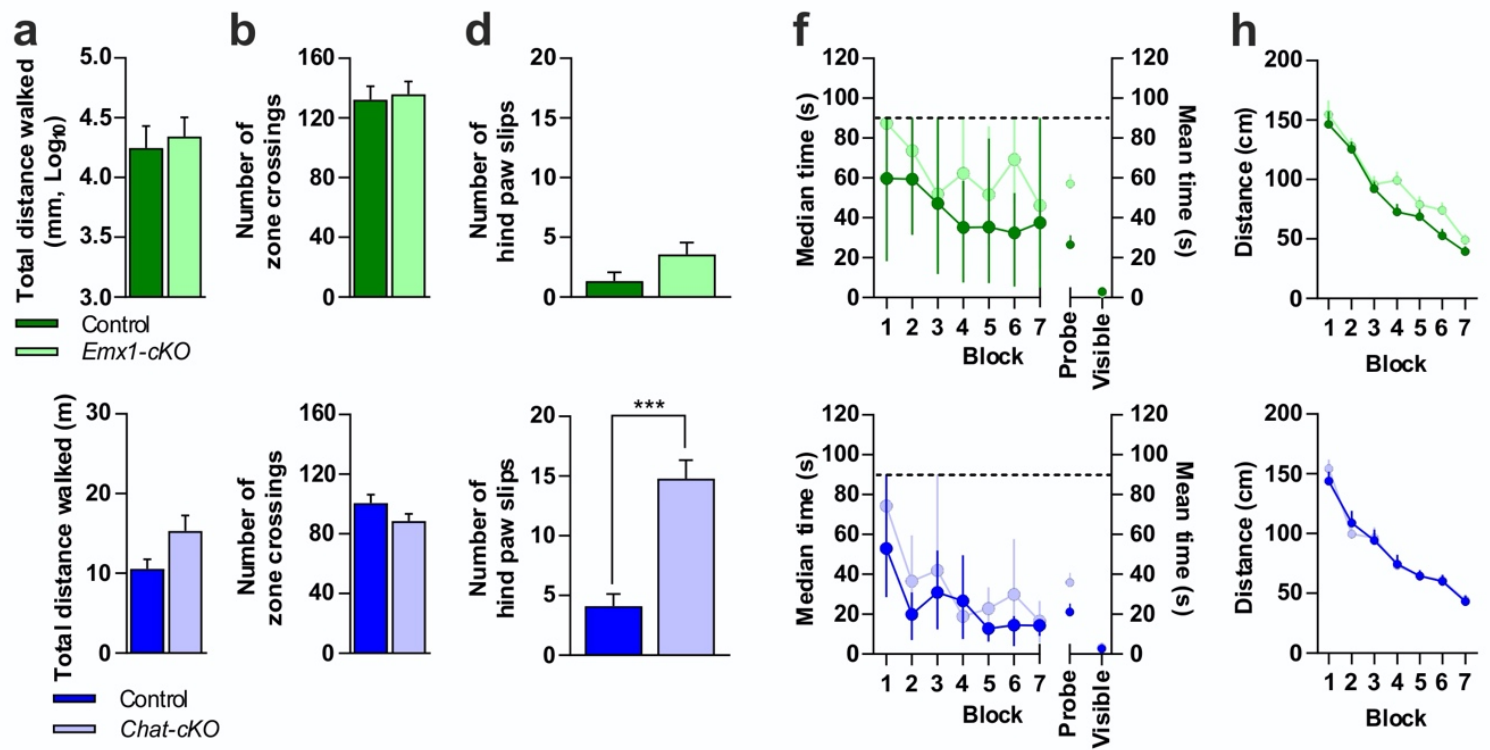

C

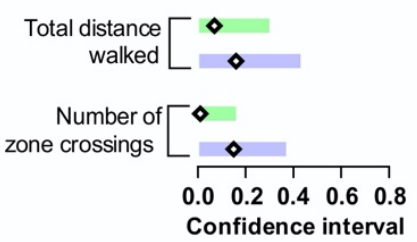

e

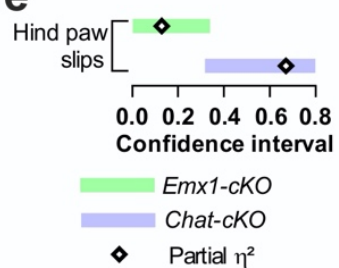

g

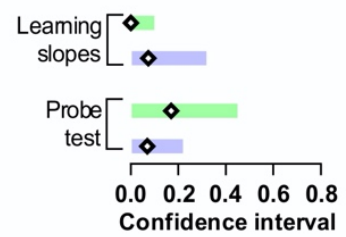

i

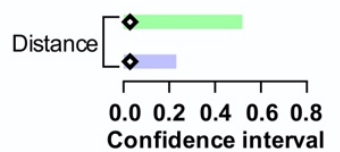

Figure S8. Restricted field of interest, hind paw coordination and spatial learning in Emx1-cKO vs. littermate control mice and Chat-cKO vs. littermate control mice. a-c The narrowness of the field of interest, expressed as the number of zone crossing in the open field $\mathbf{b}$ with the total distance walked a as covariate, is impacted neither in $\operatorname{Emx1-cKO}(n=9)$ nor in Chat-cKO mice $(n=12)$ compared to their respective control ( $n=8$ and $n=8$, respectively). c The partial $\eta^{2}$ are very low and their confidence intervals includes zero. d-e Hind paw coordination. Chat-cKO mice $(n=9)$ exhibit a high deficit when compared to their control $(n=9)$ (Student's $t=5.72, d f=16, P=0.00003$ ). On the opposite, Emx1-cKO mice $(\mathrm{n}=10)$ do not differ from their control $(\mathrm{n}=8)$ (Student's $t=1.76, \mathrm{df}=16, P=0.10)$. e The effect size of the difference in Chat-cKO $\left(\eta^{2}=0.67\right)$ exceeds the limit of impairment $(0.30)$, whereas it is not considered in Emx1-cKO mice because its confidence interval encompassed zero. (f- $\mathbf{i})$ Spatial learning in the Morris water maze. Time to reach the visible platform $\mathbf{f}$ is similar both in Emx1-cKO mice $(n=12)$ and their control $(n=11)$ and in Chat-cKO mice $(n=10)$ and their control $(n=13)$ (Student's $t$ $=0.90, \mathrm{df}=21, P=0.38$ and Student's $t=1.28, \mathrm{df}=22, P=0.21$, respectively), showing that different learning performances cannot be attributed to motor or sensorial abilities. Non-parametric statistics were used in the hidden platform version when the assumption of normality of the distributions was rejected. We examined the learning slopes with the Friedman's test for non-parametric ANOVA with repeated values. The four groups of mice learned across blocks 1 to 7 . Emx1-cKO and their control learn equally (Friedman's test for non-parametric ANOVA with repeated values: $X^{2}=21.42, \mathrm{df}=6, P=0.002$ and $X^{2}$ $=19.22, \mathrm{df}=6, P=0.004$, respectively), with similar slopes (Student's $t=0.01, \mathrm{df}=22, P=0.99$ ). Chat$c K O$ and their control also learned across blocks 1 to 7 with similar trends $\left(X^{2}=24.41, \mathrm{df}=6, P=0.0004\right.$ 
bioRxiv preprint doi: https://doi.org/10.1101/2021.10.15.464549; this version posted October 15, 2021. The copyright holder for this preprint (which was not certified by peer review) is the author/funder. All rights reserved. No reuse allowed without permission. and $\mathrm{X}^{2}=30.67, \mathrm{df}=6, P=0.00002$, respectively) and similar slopes (Student's $t=1.30, \mathrm{df}=21, P=$ 0.21). In the probe test version, the Student's $t$ in Emx1-cKO vs. control and Chat-cKO vs. controls are, respectively: Student's $t=2.22, \mathrm{df}=22, P=0.04$ and Student's $t=1.14 \mathrm{df}=21, P=0.27$. Dotted lines represent the $90 \mathrm{~s}$ cutoff. Dots indicating the visible platform values overlap. $\mathbf{g}$ The confidence intervals of the effect size for the learning slopes $\left(\eta^{2}=0.002\right.$ for $E m \times 1-c K O$ vs. control and $\eta^{2}=0.07$ for ChatcKO vs. control) include zero, indicating that the difference of the learning slope can be disregarded. The confidence intervals of the effect size for the probe test $\left(\eta^{2}=0.17\right.$ for $E m \times 1-c K O$ vs. control and $\eta^{2}$ $=0.05$ for Chat-cKO vs. controls) encompassed zero, indicating that the differences can be disregarded. h Cumulative distance from the hidden platform during the blocks. Learning was analyzed with parametric statistics (two-way mixed ANOVA with blocks as repeated-measures and cKO vs. control as between group variable). Emx1-cKO mice $(n=10)$ and their control $(n=12)$ learn equally $(F=63.18$, df $=6,120, P=7 \mathrm{E}-35$, partial $\eta^{2}=0.76$; interaction between blocks and groups $(F<1)$, with linear trend $(F$ $=209.77, \mathrm{df}=1,20, P=4 \mathrm{E}-12$, partial $\left.\eta^{2}=0.91\right)$ ) and the slopes are identical (Student's $t=0.76, \mathrm{df}=$ 20, $\left.P=0.46, \eta^{2}=0.03\right)$. Chat-cKO mice $(n=10)$ and their control $(n=11)$ also learn equally $(F=71.44$, $\mathrm{df}=6,114, P=2 \mathrm{E}-36$, partial $\eta^{2}=0.79$; interaction between blocks and groups $(F<1)$, with linear trend $\left(F=196.94, \mathrm{df}=1,19, P=1 \mathrm{E}-11\right.$, partial $\left.\left.\eta^{2}=0.91\right)\right)$. The slopes are identical (Student's $t=0.03, \mathrm{df}=$ $\left.19, P=0.98, \eta^{2}=0.00004\right)$. $\mathbf{i}$ The confidence intervals of the effect size for the learning slopes includes zero for both Emx1-cKO and Chat-cKO vs. their respective controls, indicating that the learning slopes do not differ in the two groups. Data are expressed as means + SEM (a, b, $\mathbf{d}$ and $\mathbf{h})$, or as medians with interquartile range f. ${ }^{* * *} P<0.001$. 